\title{
Some comments regarding development drifting practices with special emphasis on caving applications
}

\author{
W. Hustrulid Hustrulid Mining Services, United States of America
}

\begin{abstract}
Mass mining systems such as block caving and sublevel caving have been applied in the successful extraction of large orebodies for more than a century. Although the fundamental concepts have largely remained the same, both the designs and particularly the equipment used have seen remarkable changes over the years. Effective development drifting has played, and continues to play, a key role in the successful application and operation of caving methods. With the continuing search for an introduction of more costeffective extraction systems, 'engineered' drifting will play an even more central role in the future. An important ingredient in this regard is the acceptance of the concept of smoothwall excavation and then its whole-hearted introduction and use by mining companies. To assist in this process, the central part of this paper will deal with practical smoothwall blast design for development drifting. Experience and knowledge gained while conducting an extensive research and development programme on cautious blasting in drifting by the National Institute of Occupational Safety and Health (NIOSH) will be highlighted. The paper concludes with some ideas regarding future developments.
\end{abstract}

\section{Introduction}

Figure 1 shows the production level layout for a rather typical sublevel caving mining operation.

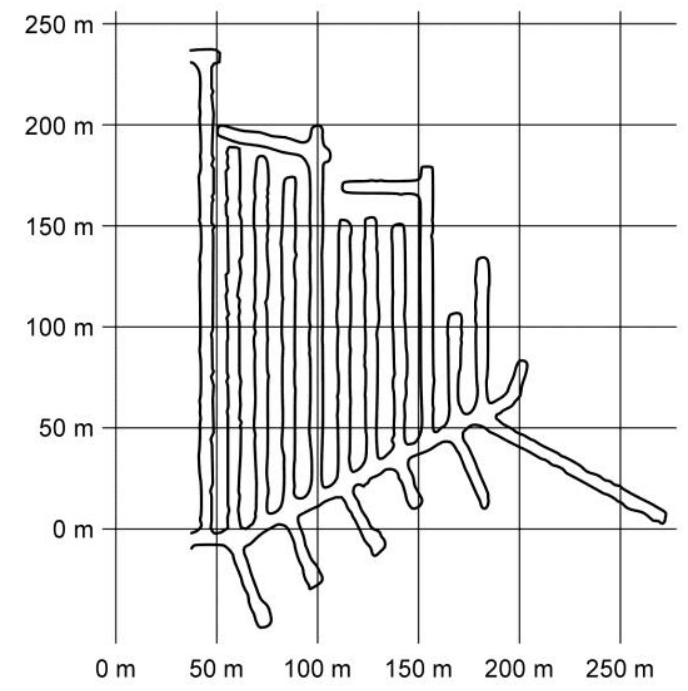

Figure 1 Typical sublevel caving layout, Ridgeway Mine (after Newcrest Mining Company, 2009, written comm.)

The corresponding longitudinal section is shown in Figure 2. 


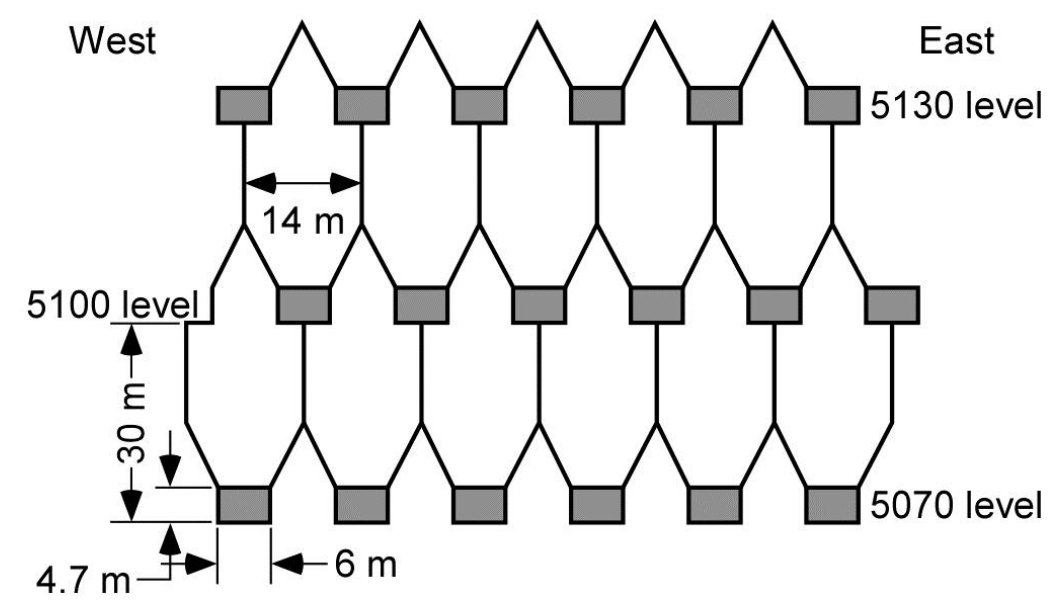

Figure 2 Longitudinal vertical section through the typical sublevel caving layout, Ridgeway Mine (after Newcrest Mining Company, 2009, written comm.)

In this particular case:

- $\quad$ sublevel interval $=30 \mathrm{~m}$

- $\quad$ sublevel drift spacing $=14 \mathrm{~m}(\mathrm{c}-\mathrm{c})$

- $\quad$ sublevel drift dimensions $=6 \mathrm{~m}$ (wide) by $4.7 \mathrm{~m}$ (high)

- drift volume $=28 \mathrm{~m}^{3} / \mathrm{m}$

- volume associated $/ \mathrm{drift}=420 \mathrm{~m}^{3} / \mathrm{m}$.

During the drifting process a volume of $28 \mathrm{~m}^{3} / \mathrm{m}$ is extracted. An ore volume of $392 \mathrm{~m}^{3} / \mathrm{m}$ remains to be extracted from the drift during the caving process. Thus, even though a relatively small percentage $(6.7 \%)$ of the total is directly extracted by drifting, it must be done properly if the following cave operation is to be successful. The drift must have the correct size and shape, and the integrity of the roof rock, in particular, must be maintained. The blasting of the rings imparts some very high dynamic loads and the loss of brow has a very adverse impact on the charging, firing and draw operations. The bottom line is that the development drifting must be done with care and the as-built should closely resemble the as-designed.

As an open pit mine approaches the end of its economic life, today the focus is on extending that life by going underground. For large, massive deposits, block or panel caving becomes a logical candidate if the rock mass is amenable to caving. A rather concentrated development effort is expended at the bottom of a high column of rock for creating the undercut which facilitates the caving and the subsequent extraction of the caved rock. Figure 3 shows a portion of the undercut level for the Esmeralda Mine in Chile.

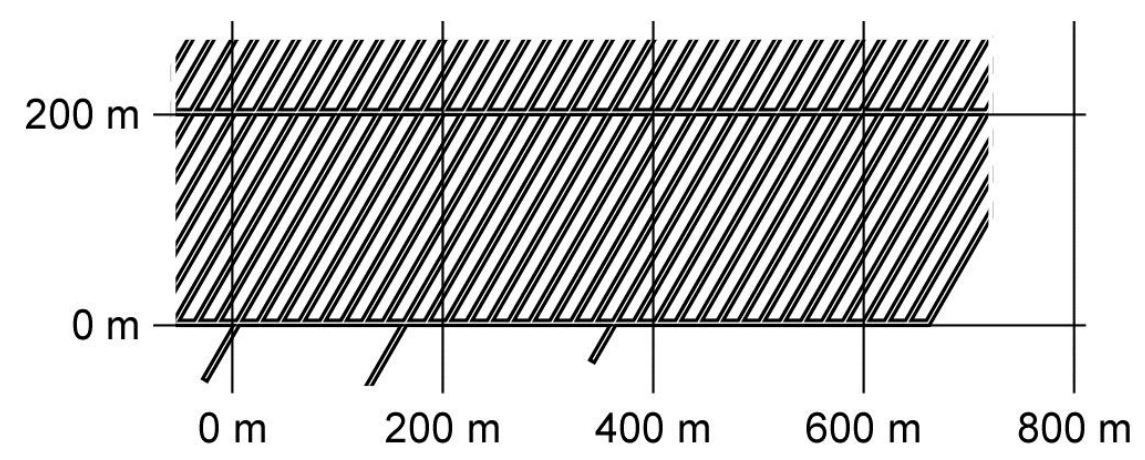

Figure 3 Plan view of a portion of the undercut level, Esmeralda sector, EI Teniente Mine, Chile (after Barraza, 2009, written comm.) 
The following applies:

- $\quad$ drift size $=3.6 \times 3.6 \mathrm{~m}$

- $\quad$ drift spacing $=15 \mathrm{~m}$.

In plan, the percent extraction through drifting is $24 \%$. The corresponding production level layout which lies $18 \mathrm{~m}$ below the undercut level is shown in Figure 4.

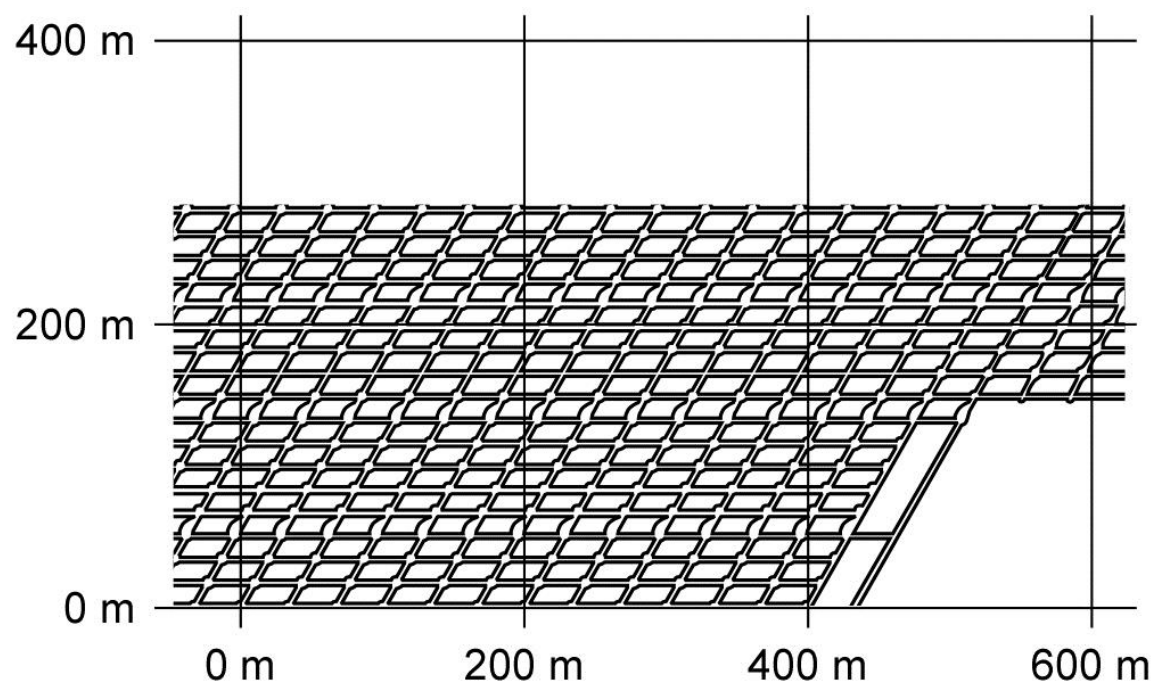

Figure 4 Plan view of a portion of the production level, Esmeralda sector, El Teniente Mine, Chile (after Barraza, 2009, written comm.)

The characteristics are:

- $\quad$ drift size $=3.6 \times 3.6 \mathrm{~m}$

- $\quad$ extraction drift spacing $=30 \mathrm{~m}(\mathrm{c}-\mathrm{c})$

- drawpoint drift spacing $=17.32 \mathrm{~m}(\mathrm{c}-\mathrm{c})$ measured along the extraction drift

- angle between the extraction drift and the drawpoint drift $=60^{\circ}$.

In plan, the percent extraction by drifting is $33 \%$. The volumetric percent extraction by drifting, based on the distance from the undercut level to the cave above, equals $180 \mathrm{~m}$ which is only $1.14 \%$ - a very small number. Based upon development alone, it is easy to understand the attraction of this method compared to sublevel caving, for example. Successful completion of the drifting on the undercut is required for the remaining steps of the undercutting process to be successful. If the undercut is not completed as required, there can be heavy concentrated loads placed on the extraction level and extraction points. The production level development must be conducted in such a way as to retain, as much as possible, the strength characteristics of the host rock. This level must undergo the rigors of the undercutting process followed by the effects of extracting the overlying ore block. Should the production level collapse, for example, or even if some drawpoints are lost, the low specific development numbers projected in the different project stages quickly turn to a sad fiction. The bottom line is that the development drifting must be done with care and the as-built should closely resemble the as-designed.

In reviewing the technical literature dealing with blast design, in general, but with regard to drifting with perimeter control, in particular, it has become very clear that rather little has been written with the aim of providing practical tools for mine engineers that can be easily applied to improve drifting practices. NIOSH, as part of their programme to improve the general safety and overall working conditions in underground mines, has planned and is currently conducting a research and development programme focused on encouraging the application of careful/cautious blasting in underground mining. The programme has a number of different facets. The one reported upon in this paper deals with the design methodology and procedures for estimating the required damage radius as a function of the explosive and the rock. Some 
simple design curves are presented which can be easily applied to provide first approximations. The application of the procedures is demonstrated by way of example.

\section{Some general background}

\subsection{Placing this contribution in an historical context}

The following material has been excerpted from the book "Principles of Metal Mining" written by J.H. Collins in 1875:

The art of mining is very ancient, and eminently progressive. The use of gunpowder for blasting in hard ground, said to have been first used in the parish of Breage in Cornwall, is scarcely three centuries old; and even yet the ancient mode of rendering the rock brittle, by first heating it by means of a fire of brushwood kindled in the "end" and then throwing cold water upon it, is still in use in some of the continental mines.

These facts may serve to illustrate the extreme conservatism of the race of miners; a conservatism which has induced many miners to look with dislike, and even with contempt, upon every kind of knowledge, except that which may be learnt in the mine itself.

Such prejudices are now, however, happily passing away, and the best miners are beginning to see that the study of various branches of science may not only accompany, but precede with advantage, actual work in the mine.

The process of blasting deserves careful study from everyone engaged in mining operations, whether in open works or underground. It is, of course, to be learnt by practice only, but some few general remarks will no doubt be useful. The process in outline is as follows:

- A hole is first made in the rock by means of the mallet and borer. In general one man holds the borer while it is struck or "beaten" by one, two, or three strikers who deliver heavy blows alternately upon its head, the holder giving it about one-eighth of a turn after every blow. A little water is fed into the hole from time to time, and at intervals the "sludge" is withdrawn from the hole by means of a "swab-stick." In this way a hole is bored from 1 inch to 2 inches in diameter at the rate of from 4 to 30 inches per hour, according to the hardness of the rock.

- The hole being bored to its proper depth, a quantity of gunpowder is placed in it.

- A piece of safety fuse long enough to reach the powder is placed in the hole, and it is filled up with hard clay, sand, broken brick, or other tamping material, which is driven in firmly with the tamping bar.

- Sometimes gun-cotton, nitro-glycerine, or dynamite are used instead of gunpowder, when tamping becomes less necessary, or even altogether needless.

- The hole having been charged, the outer end of the fuse is set on fire, the workmen retire to a safe place, and when the fire reaches the powder or other material used, it explodes with great violence.

- In general the holes need not be so large or so deep for dynamite, gun-cotton, or nitroglycerine as for gunpowder.

The miner should so place his hole that it may encounter as nearly as possible an equal resistance in every direction.

Much practice, observation, and judgment will be needed before he will be able to properly apportion the charge to the amount of work to be done.

This paper, although written 135 years after the publication of this book, deals, in particular, with the last sentence. Surprising as it might seem, work is still needed in helping blasting engineers and miners decide how to properly apportion the charge based upon the work to be done. Specifically, it is hoped that this paper will provide some new tools for designing drifting rounds based around the modern tools available today.

\subsection{Brief description of the explosive action}

The following explanation of the blasting process has been extracted from the classic book on blast design "The Modern Technique of Rock Blasting" by U. Langefors and B. Kihlström published in 1963. 
Within some thousandths of a second after the initiation of the explosive, there occurs in a charged hole a series of events which, in drama and violence, have few equivalents in civil technology. The chemical energy of the explosive is liberated and the compact explosive becomes transformed into a glowing gas with an enormous pressure which, in a densely packed hole, can amount to and exceed 100,000 atmospheres. The amount of energy developed per unit of time, even in a tiny hole drilled with a handheld machine, is of the order of magnitude of 25,000 MW. That is, to say, it exceeds the power of most of the world's present largest power stations. This is not due to the fact that the amount of energy latent in the explosive is extremely large but to the rapidity of the reaction $(2,500-6,000 \mathrm{~m} / \mathrm{s})$. What is especially characteristic of the explosive as a tool in rock blasting is its ability to provide concentrated power in a limited part of the rock.

The high pressure to which the rock is exposed shatters the area adjacent to the drill hole and exposes the space beyond that to vast tangential strains and stresses. These take place under the influence of the outgoing shock wave which travels in the rock at a velocity of 3,000-5,000 m/s. Around a hole with a diameter of $40 \mathrm{~mm}$ in primary rock the thickness of the crushed zone is of the same size as, or slightly less than the radius of the hole. The system with radial cracks issuing from the center of the hole as a result of the tangential stresses, the so-called rose of cracks, extends considerably further. In the example mentioned it can extend from some decimeters to about a meter. Consequently, the first cracks have been completed in fractions of a millisecond. In Figure 5, the front of the shock wave (luminous circle) from a cylindrical charge is seen to propagate at a much greater velocity than the radial cracks (central dark section).

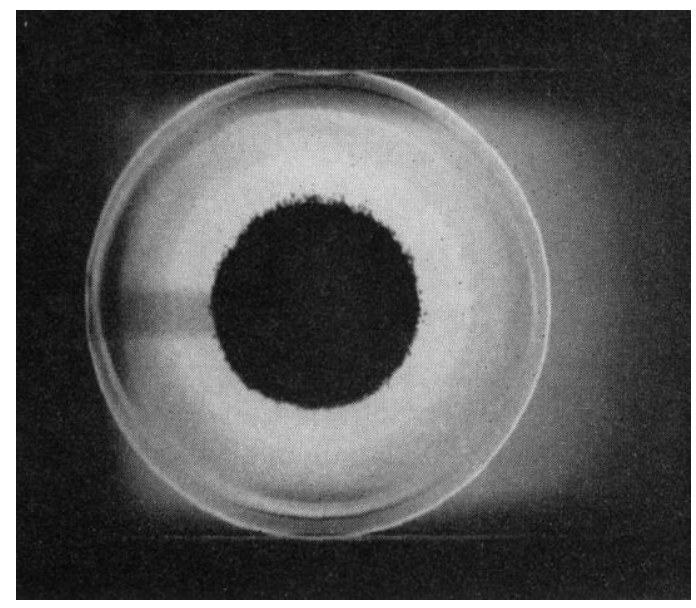

Figure 5 The results of a detonation in a transparent lucite plate with a central hole and the source of light from behind. The picture is taken $15 \mu \mathrm{sec}$ after detonation with an exposure time of $0.03 \mu$ sec (after Langefors and Kihlström, 1963)

The lateral pressure in the shock wave is, to begin with, positive when the shock wave arrives, and then falls rapidly to negative values. This implies a change from compression to tension. Near the hole the strain forces are even greater than the compression in the front of the shock wave. As the rock is less resistant to strain than to compression the primary cracks will chiefly occur under the influence of tensile forces with resulting pronounced radial cracks.

During this first stage of the cracking there is practically no breakage. If the drill hole with its charge goes straight into the rock without any adjacent surface parallel to the hole the shock wave fades out without any further effect. The remaining pressure of the gases in the drill hole slightly widens the cracks. But if the environment of the rock is studied after blasting, for example on a level some few feet below the top face of the rock, at right angles to the hole only the radial cracks will be found. The drill hole has been slightly widened to normally less than double the diameter by crushing and plastic deformation. As the cracks in this case have contracted again after the blasting it may even be difficult to discover them with the naked eye. They can easily be observed if some of the rock close to the hole is removed and sawn or treated in some other way. In model scale experiments conducted in Plexiglas, which is transparent, the entire picture of the cracks can be studied (see Figure 6). 


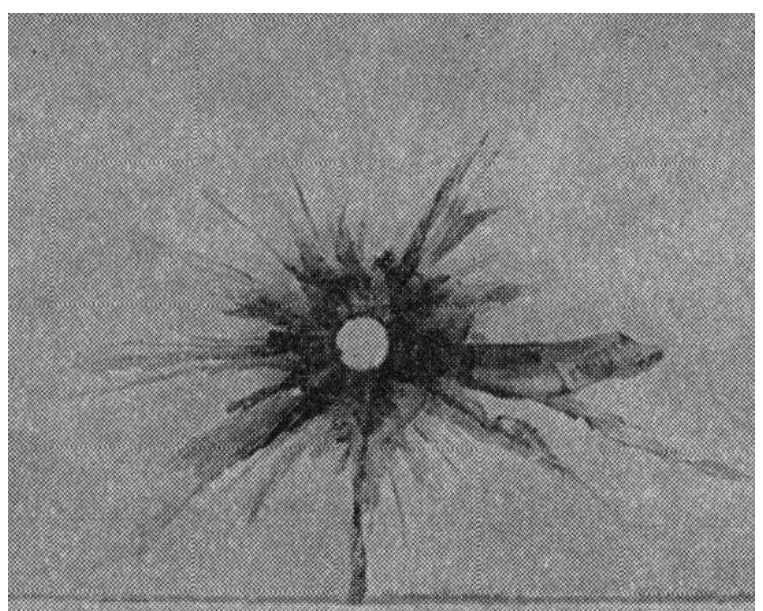

Figure 6 Crack pattern produced in a Plexiglas plate due to the detonation of an explosive charge (after Langefors and Kihlström, 1963)

The last stage of the breakage is a slower process. Under the influence of the pressure of the gases from the explosive, the primary radial cracks expand, the free rock surface in front of the drill hole yields and is moved forward. This may be described as a quasi-static process in which the strain picture at any moment decides the continuation of the cracks just as in the case of a static load. When the frontal surface moves forward, the pressure is unloaded and the tension increases in the primary cracks which incline obliquely forward. If the burden is not too great, several of these cracks expand to the exposed surface and complete loosening of the rock takes place. The burden is consequently torn off and the maximum effect per drill hole and quantity of charge is attained (assuming) it is possible for the burden in front of a hole to move forward freely when the charge detonates.

Figure 7 shows a detonating Pentaerythritol tetranitrate (PETN) charge in a $5.2 \mathrm{~mm}$ diameter hole in Plexiglas (Persson et al., 1994). The leading edge of the shockwave and the slower development of the cracking are clearly seen. According to Persson et al. (1994).

The material behind the shock front is completely transparent indicating that the material is deforming plastically without cracking. At a certain distance behind the front, the material becomes opaque because of the radial cracks. The cracks do not start at the hole wall but at a point one or two radii further out and then propagate radially outward and inward.

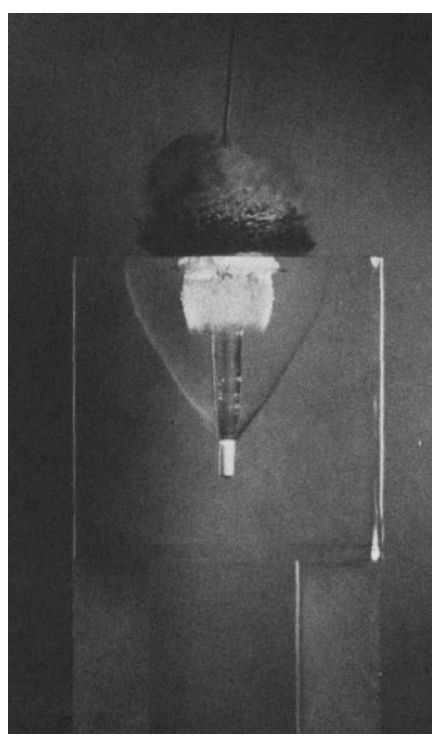

Figure 7 High speed photograph of a detonating charge in Plexiglas (after Persson et al., 1994) 
Figure 8 is a section through a Plexiglas cube after the detonation of a low-density PETN charge in a $3 \mathrm{~mm}$ diameter hole. Persson et al. (1994) note:

The hole has returned to its original size after expanding to 2 to 3 times this size. The region near the hole has probably yielded without cracking. The intermediate zone has fractured by shear cracks and the outer region by radial cracks.

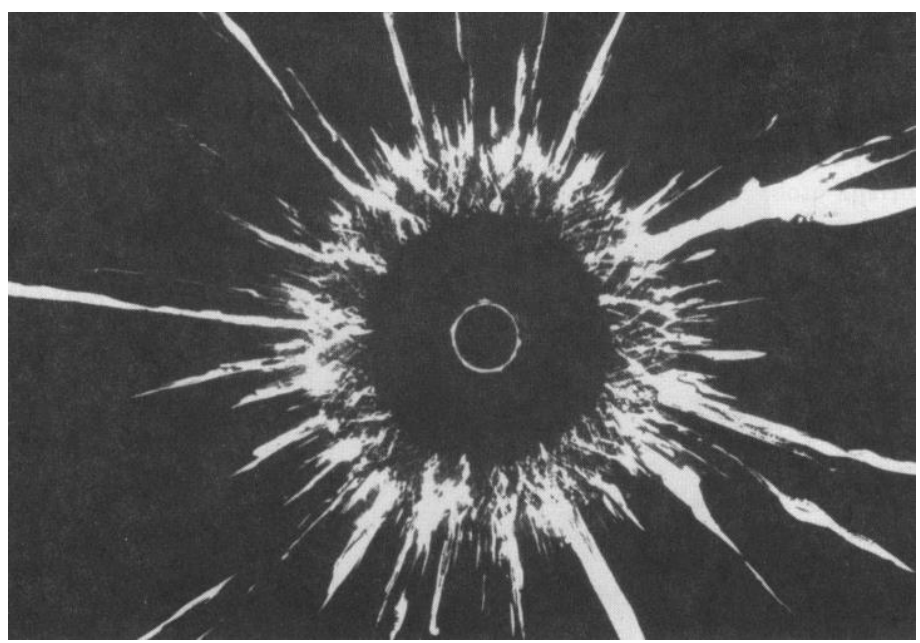

Figure 8 Slice through a Plexiglas cube after detonation by a charge of PETN (after Persson et al., 1994)

Although it is, of course, easiest to observe the fracturing patterns in transparent materials such as glass and Plexiglas, such patterns can also be observed in rock. Olsson and Bergqvist (1993) have presented the results of carefully conducted tests in Vånga granite in which crack growth was studied for different explosive and hole diameter combinations. Figure 9 is one such example. In this case, detonating cord was used in a $35 \mathrm{~mm}$ diameter hole. Due to the highly de-coupled charge, there is a very small crushed zone directly at the hole boundary and then a zone of fairly dense cracking followed by a zone of radial cracking. As seen, this test which was located quite remote from a free surface presents a very symmetrical breakage pattern which can be broken into zones using circles of different radii centred on the charge axis.

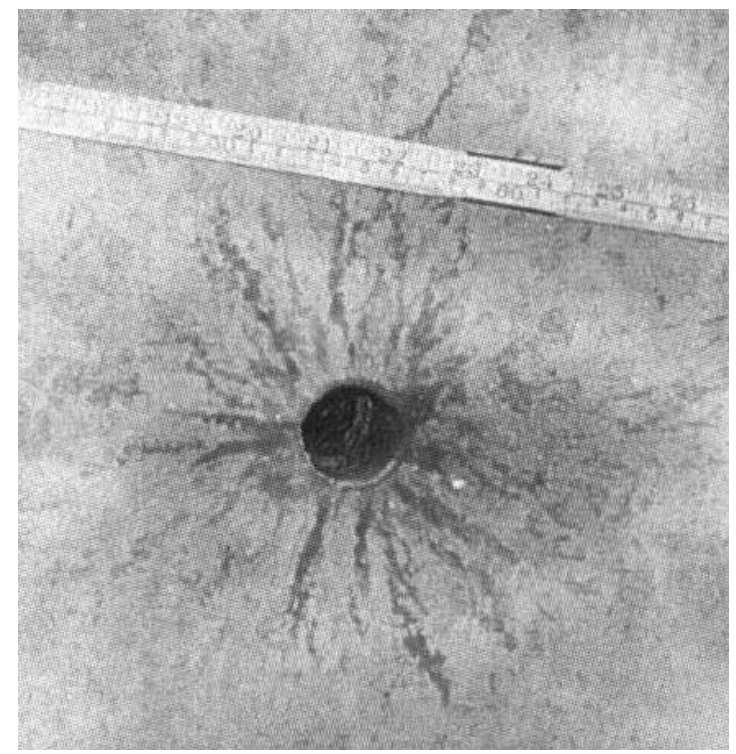

Figure 9 The cracking pattern observed in Vånga granite when using detonating cord in a 35 mm diameter hole (Olsson and Bergqvist, 1993) 
There are many other such examples appearing in the technical literature. The important point is that during the initial and middle stages of an explosion, the cracking pattern, assuming isotropic conditions, is symmetrical with respect to the charge axis. It is only when the presence of a free surface is communicated back to the explosion zone, that the fracture pattern changes. Based upon examples such as these, acceptance of the concept of a damage radius associated with a particular explosive in a given rock becomes quite natural. Once accepted, the practical problem becomes one of defining and predicting the damage radius.

\subsection{Impact of the damage radius concept on traditional perimeter row design}

Perimeter control blasting is commonly applied to the roof but increasingly it is being applied to the walls as well. Figure 10 shows the different design sectors commonly distinguished for a drift round.

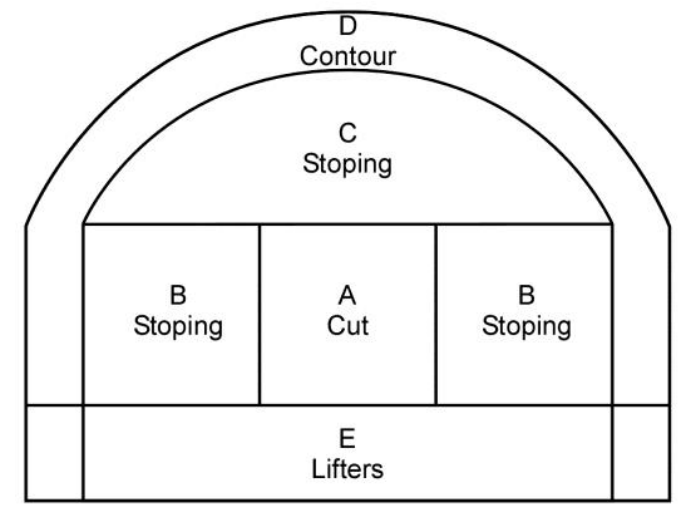

Figure 10 Diagrammatic representation of the design sectors involved in a drift round (after Holmberg, 1982)

One begins by designing the cut, the contour and the lifter sectors. When the particular designs for each of the sectors have been completed, they are added to the overall drift design. The so-called stoping holes are then added as needed. The implication is that the holes/explosives included in the different sectors are responsible for removing the associated rock. In the case shown in Figure 11, the drift is $7 \mathrm{~m}$ wide and $5 \mathrm{~m}$ high. The width (the 'burden') of the contour sector is about $0.6 \mathrm{~m}$, particularly in a hard, strong rock, it is expected that the amount of explosive charge required to remove the contour sector of rock is quite high and this subsequently would place quite strong requirements on the perimeter row design.

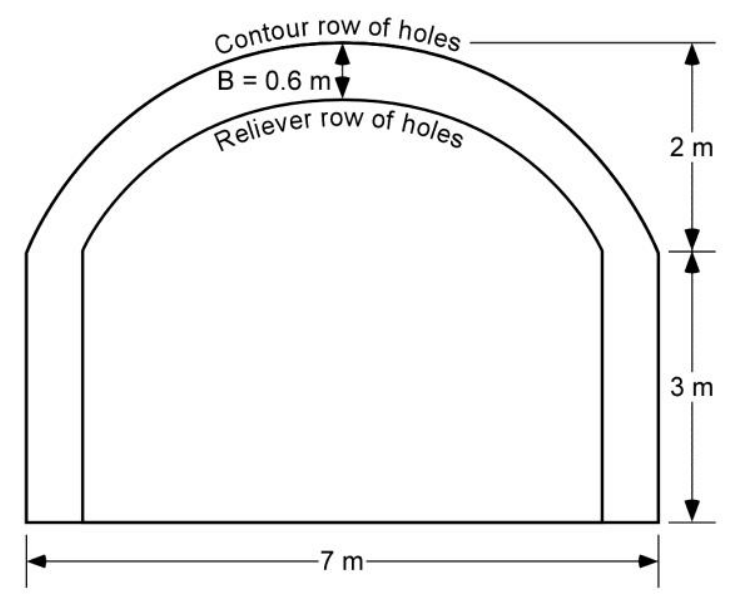

Figure 11 Contour sector bounded by the contour row and the easer row

In reality, as shown in Figure 11, the contour strip of rock is bounded on the inside by the easer (reliever) row of holes and on the outside by the perimeter (contour) row. In keeping with the damage radius notion introduced in the previous section, the detonation of the easer row will produce damage in the contour sector. This is shown diagrammatically in Figure 12. As will be discussed in some detail later, the idea is to design 
the easer holes so that their associated damage radius extends to the desired drift perimeter. Figure 12 shows the case when the damage radius $\left(\mathrm{R}_{\mathrm{d}}\right)$ equals $0.6 \mathrm{~m}$, which equals the contour row 'burden'.

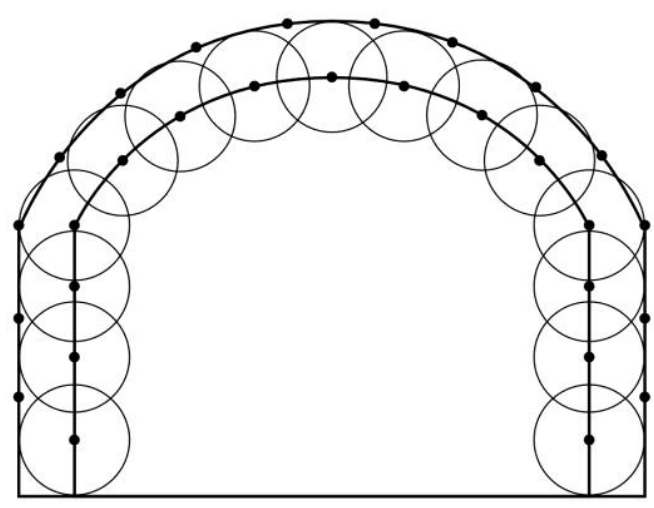

Figure 12 Addition of the damage circles

If this is the case, after the firing of the easer holes, the amount of fresh/undamaged rock is only the small cusp of rock remaining between damage circles. With this in mind, the breaking demand on the perimeter holes is substantially reduced. This is a prime reason why the use of high strength detonating cord often functions quite well as a perimeter control explosive since the primary function has become one of smoothing rather than primary breaking.

The potential contributions of the perimeter, easer and stoping holes in breaking the contour sector of rock and eventually damaging the perimeter rock is shown in the well-known drawing of Holmberg and Persson (1979) and Holmberg (1982) (Figure 13).

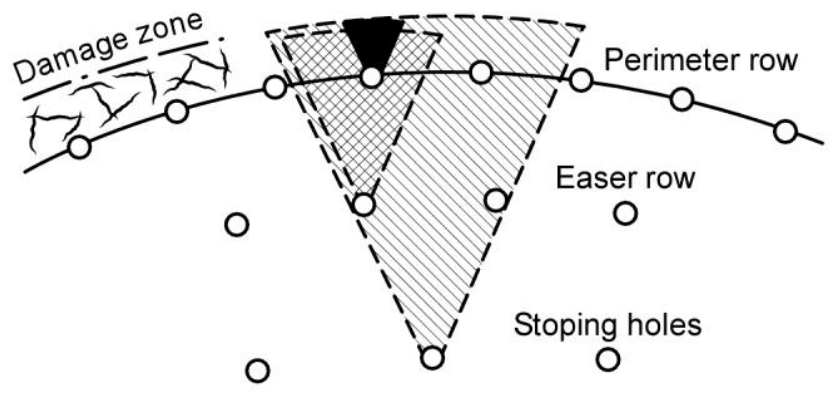

Figure 13 The charge concentrations in the holes close to the contour are adjusted so that the damage zone from each hole coincides (after Holmberg and Persson, 1979; Holmberg, 1982)

Although this representation is true in principle, in practice it is really only the easer and perimeter holes which are involved. This latter situation will be assumed here.

\section{Discussion of the NIOSH design procedure}

The key to the NIOSH approach (Hustrulid and Johnson, 2008) is the assignment of a 'practical' radius of damage $\left(R_{d}\right)$ to each blasthole/explosive combination being considered for use in the particular rock mass. By practical radius of damage, it is meant that if the rock mass lying outside of this ring were removed, the rock remaining within the ring would easily break apart. As can be seen in Figure 14, the practical damage zone consists of both crushing and cracking components. 


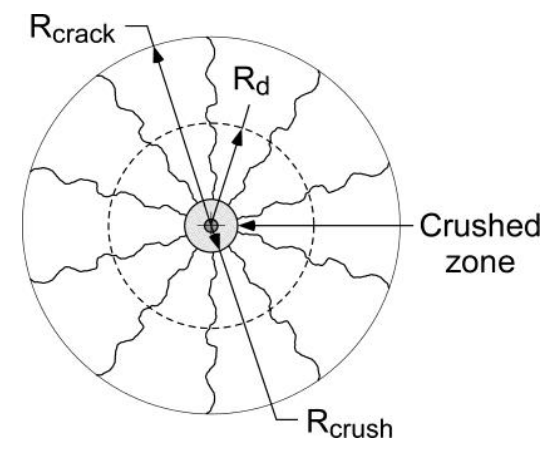

Figure 14 Diagrammatic representations of the crushed, cracked and damaged zones surrounding a blast hole

To demonstrate the technique, consider the $4.5 \mathrm{~m}$ wide by $4 \mathrm{~m}$ high drift with arched roof shown in crosssection (Figure 15). The perimeter (walls and roof) is to be excavated using smoothwall blasting techniques. The following steps are used:

- Step 1: design the easer row.

- Step 2: add the contour holes.

- Step 3: design the lifters.

- Step 4: add the cut.

- Step 5: add fill-in holes as required.

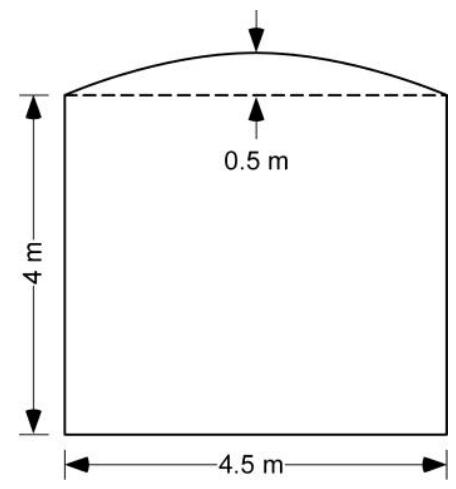

Figure 15 Example drift shape

At this point in the discussion it will be assumed that $R_{d}=0.5 \mathrm{~m}$ for the fully-coupled easer row holes. The technique used for calculating $\mathrm{R}_{\mathrm{d}}$ will be presented later in the paper. To start the design, parallel shells located at distances of $R_{d}$ and $2 R_{d}$ inside the desired contour are drawn as shown in Figure 16.

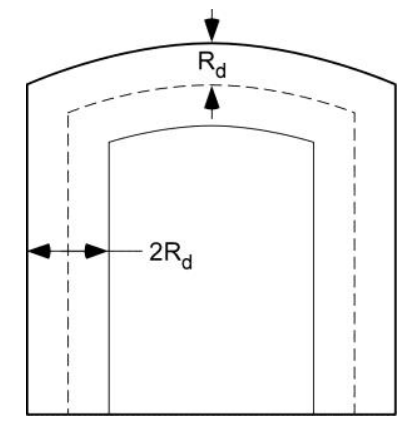

Figure 16 First step in the easer row design 
Next, circles of radius $R_{d}$ are added. The centre of the circle corresponds to a future easer row hole location. Figure 17 shows the placement of the easer row holes in the 'just-overlapping' scenario.

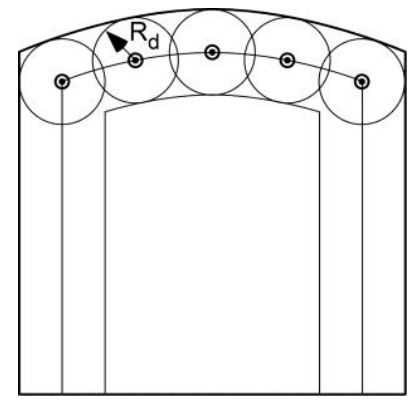

Figure 17 Initial placements of the easer row roof holes

As can be seen, there is a considerable amount of 'untouched' rock between the as-designed coverage and the perimeter. This is overcome by translating the holes along the design line so that they more fully overlap. Figure 18 shows one possible arrangement.

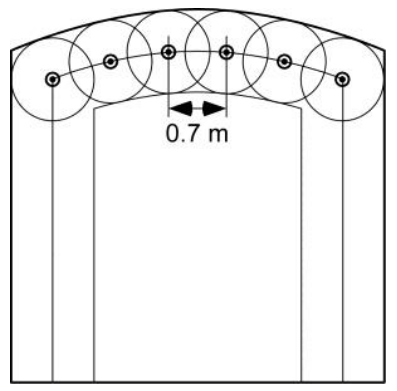

Figure 18 Final placements of the easer row roof holes

In this particular case, the distance between the easer row holes is $1.4 \mathrm{R}_{\mathrm{d}}$, or $0.7 \mathrm{~m}$. In Figure 19, the easer rows have been added to each of the walls.

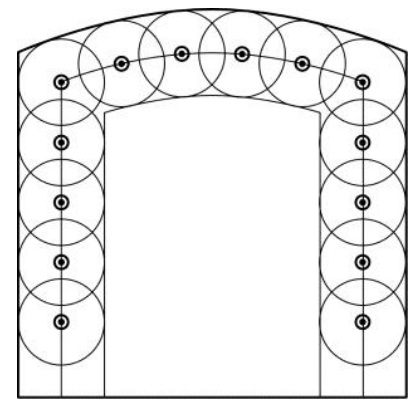

Figure 19 Addition of the easer row wall holes

In Step 2, the contour row holes are positioned to 'smooth out' the surface created by the easer row holes. The first holes placed are in the drift corners. They have the required look-out and look-up angle to provide the space needed for drilling the next round. The remaining holes along the roof are placed to remove the remaining rock cusp between adjacent damage circles. The design basis for the contour row is presented later in the paper. As can be seen, the amount of virgin rock associated with each hole (the burden) is rather small (Figure 20). 


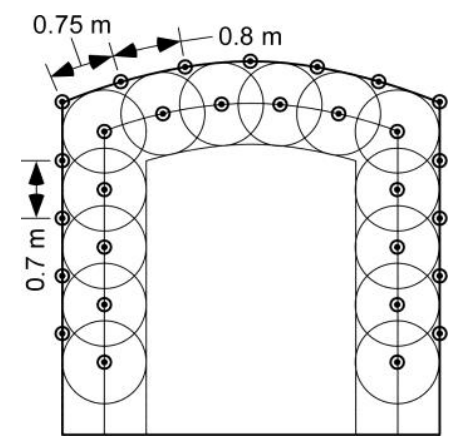

Figure 20 Addition of the contour holes

In Step 3, the lifters are added. They have extra work to do both working against gravity and against the weight of the overlying pile, so, even if they are the same diameter as the other holes in the round, they are often charged with a more energetic explosive. In this particular case, it is assumed that the associated $\mathrm{R}_{\mathrm{d}}$ is $0.7 \mathrm{~m}$. A lifter hole is placed in each corner and the remaining holes are positioned to cover the remaining distance. To improve floor evenness, the circles are overlapped (Figure 21).

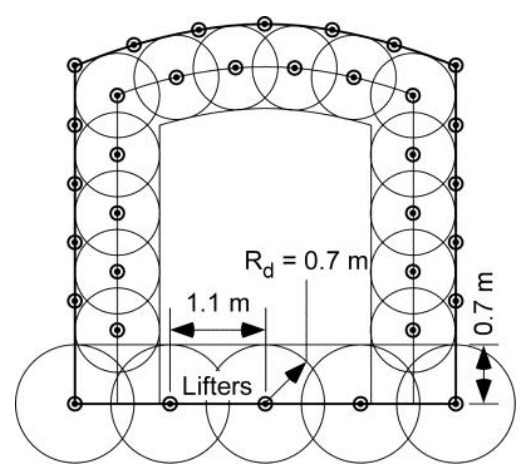

Figure 21 Lifters added to the design

In Step 4, a four-quadrangle cut with a final side dimension of $1.4 \mathrm{~m}$ has been selected for use. A single, large diameter, uncharged hole provides the initial free surface. The numbers refer to the number of the half second delay (No. 1 is $0.5 \mathrm{~s}$ delay, No. 2 is $1.0 \mathrm{~s}$ delay, etc.) being used. The cut has been superimposed on the design in Figure 22.

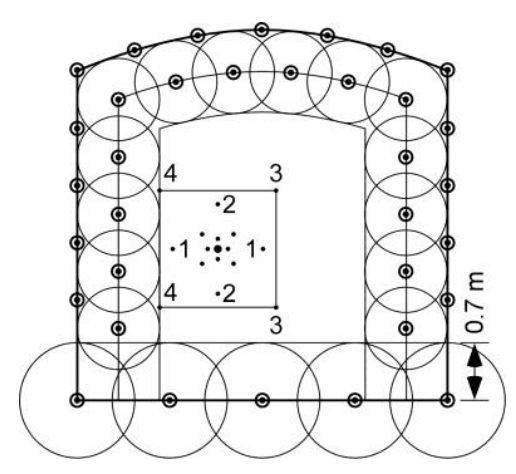

Figure 22 Addition of the cut to the design

Finally, additional 'stoping' holes are added to fully cover the face. The final result is shown in Figure 23. 


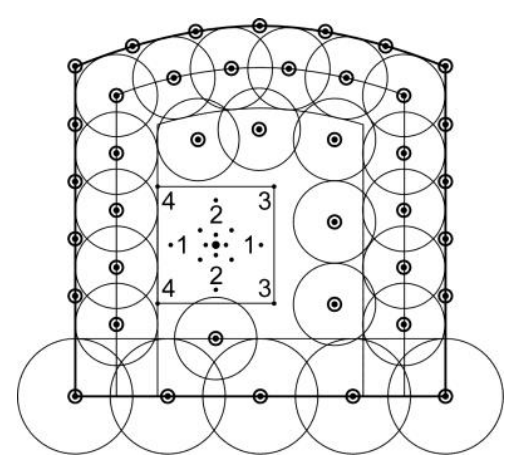

Figure 23 Completion of the design with the addition of stoping holes

\section{$4 \quad$ Methods for determining the practical damage radius}

\subsection{Introduction}

A fundamental part of the NIOSH design approach is the assignment of a blast damage radius to each hole rather than an influence area expressed in terms of hole burden and spacing dimensions. The latter largely neglects any fracturing occurring behind the hole. Since this is a fundamental departure from standard practice, some effort has been made to identify and further develop approaches that could provide practical guidance to engineers for assigning the required radius. In the process of developing and constructing the circles, a side benefit is a very useful depiction of the explosive energy coverage. One can then have a simple, but solid, basis for adding, moving or subtracting holes. In this section, a rather detailed discussion of five methods for assigning a damage radius is presented. The methods range from empirically/observation based to some with very solid theoretical roots. The approaches have been presented in some detail probably much more detail than is required and desired by the blasting engineer - and this reader is encouraged to skip to Section 5 where a practical example is worked using all of the approaches. The reader may then decide to return to this section for further clarification. It is emphasised that this is a work in progress and that further improvements are expected.

\subsection{Modified Ash Energy-based Approach}

In 1963, Ash (1963) published his now classic papers dealing with blast design in open pit mines and quarries. Figure 24 is an isometric representation of a bench with the design parameters indicated.

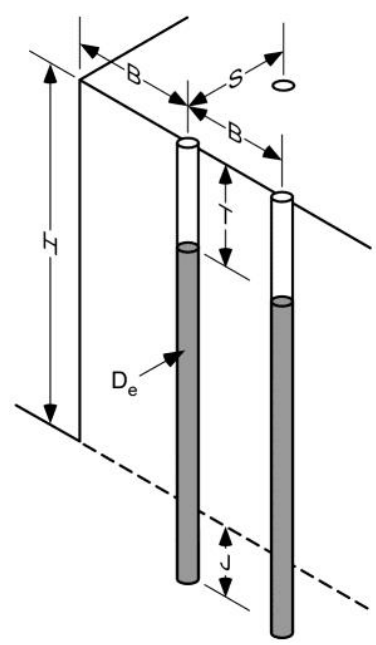

\section{Figure 24 Isometric view of a bench blast design}

Using field data collected from a large number of operations, Ash (1963) summarised the different design parameters. He found that the subdrill $(\mathrm{J})$, the stemming $(\mathrm{T})$, the spacing $(\mathrm{S})$ and the bench height $(\mathrm{H})$ could 
all be related to the burden (B). Most importantly, he found that for fully charged holes the burden (B) was related to the blasthole diameter $\left(\mathrm{D}_{\mathrm{e}}\right)$.

$$
B=K_{B} D_{e}
$$

where:

$\begin{array}{lll}B & = & \text { burden. } \\ K_{B} & = & \text { constant. } \\ D_{e} & = & \text { hole diameter. }\end{array}$

The value of $K_{B}$ varied with both the rock and the explosive. Ash (1963) provided the following recommendations:

- for light explosives in dense rock use $K_{B}=20$

- for heavy explosives in light rock use $\mathrm{K}_{\mathrm{B}}=40$

- for light explosives in average rock use $\mathrm{K}_{\mathrm{B}}=25$

- for heavy explosives in average rock use $K_{B}=20$.

Over time, his work has been shown to have very successfully captured the experience and today, if one examines open pit/quarrying experience, one finds that with the possible exception of the hole spacing relationship, the ratios are largely followed. In 1999, Hustrulid (1999) as part of his book "Blasting Principles for Open Pit Mining" proposed a design procedure based on energy coverage. It was assumed that the holes were completely charged with explosive, i.e. fully-coupled. The radius of the damage circle used in this approach was obtained by equating available explosive energy to that required to produce acceptable fragmentation. In this regard, it was assumed that the use of ANFO with density $0.85 \mathrm{~g} / \mathrm{cm}^{3}$ to blast an average rock of density $2.65 \mathrm{~g} / \mathrm{cm}^{3}$ yielded satisfactory results when $K_{B}=25$. The formula expressing the ratio $\mathrm{K}_{\mathrm{B}}$ for other rock explosive combinations becomes:

$$
K_{B}=25 \sqrt{\frac{\rho_{e} s_{A N F O}}{\rho_{A N F O} s_{1 A N F O}}} \sqrt{\frac{2.65}{\rho_{\text {rock }}}}
$$

where:

$$
\begin{array}{lll}
\rho_{e} & = & \text { density of the explosive used }\left(\mathrm{g} / \mathrm{cm}^{3}\right) . \\
s_{\text {ANFO }} & = & \text { weight strength of the explosive relative to ANFO. } \\
\rho_{\text {ANFO }} & = & \text { density of ANFO }=0.85 \mathrm{~g} / \mathrm{cm}^{3} . \\
s_{\text {IANFO }} & = & \text { weight strength of ANFO relative to ANFO }=1 . \\
\rho_{\text {rock }} \text { or } \rho_{r}= & \text { density of the rock mass }\left(\mathrm{g} / \mathrm{cm}^{3}\right) .
\end{array}
$$

This formula provides values of $K_{B}$ which are roughly in keeping with the Ash (1963) recommendations regarding the effect of explosive energy and rock density. Based simply on the geometry of just-touching circles:

$$
B=2 R_{d}
$$

the basic Ash (1963) burden formula becomes:

$$
B=2 R_{d}=K_{B} \cdot D_{e}=K_{B} \cdot 2 r_{h}
$$

where:

$r_{h} \quad=\quad$ hole radius.

or:

$$
R_{d}=K_{B} r_{h}
$$

finally, one obtains the relationship: 


$$
\frac{R_{d}}{r_{h}}=25 \sqrt{\frac{\rho_{e} s_{A N F O}}{\rho_{A N F O}}} \sqrt{\frac{2.65}{\rho_{\text {rock }}}}
$$

it is recognised that:

$$
\frac{\rho_{e} s_{A N F O}}{\rho_{A N F O}}=R B S
$$

where:

RBS $=$ relative bulk strength to ANFO.

The $R B S$ is often provided by explosive suppliers. Thus, Equation (5) becomes:

$$
\frac{R_{d}}{r_{h}}=25 \sqrt{R B S} \sqrt{\frac{2.65}{\rho_{\text {rock }}}}
$$

Figure 25 is a simple design curve that can be used to solve for $R_{d} / r_{h}$ given the $R B S$. It assumes fully-coupled charges and a rock density of $2.65 \mathrm{~g} / \mathrm{cm}^{3}$.

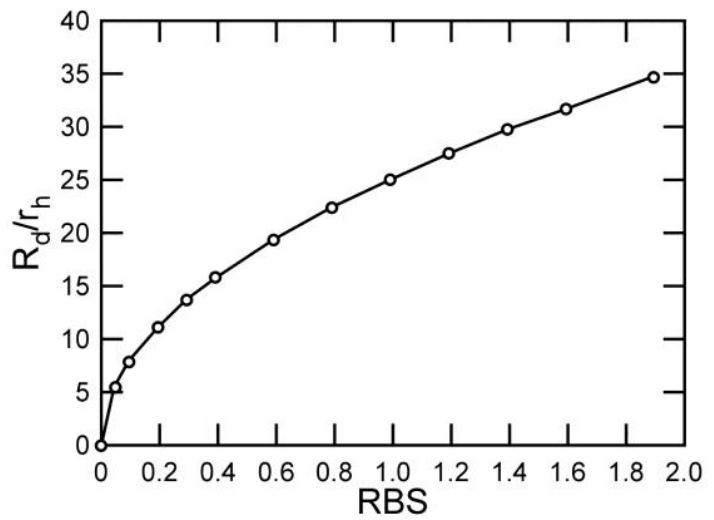

Figure 25 Plot of $R_{d} / r_{h}$ versus $R B S$ for the Modified Ash Energy-based Approach

As can be seen, the approach is quite simple involving available explosive properties and the density of the rock as inputs. Thus, it is attractive for mine application. Since it is based on the Ash burden formula and energy factors, it has been given the name "Modified Ash Energy-based Approach".

Equation (5) can be adapted for use with de-coupled charges. The general equation is:

$$
\frac{R_{d}}{r_{h}}=25 \sqrt{\frac{\rho_{e} s_{A N F O}}{\rho_{\text {ANFO }}}\left(\frac{A_{e}}{A_{h}}\right)} \sqrt{\frac{2.65}{\rho_{\text {rock }}}}
$$

where:

$A_{e} \quad=\quad$ cross-sectional area of the explosive

$A_{h} \quad=\quad$ cross-sectional area of the hole.

If the explosive is in a cylindrical package and extends the length of the hole, Equation (8) can be written as:

$$
\frac{R_{d}}{r_{h}}=25\left(\frac{d_{e}}{d_{h}}\right) \sqrt{\frac{\rho_{e} s_{A N F O}}{\rho_{A N F O}}} \sqrt{\frac{2.65}{\rho_{\text {rock }}}}
$$

\subsection{Modified Ash Pressure-based Approach}

In the previous section, it was assumed that the Ash (1963) recommendations could be extrapolated to other explosives and rock types based on energy. One can argue that some other parameter should be used instead. 
One logical parameter is the borehole wall pressure. Here, the foundation for developing such a relationship is the thick-walled cylinder approximation for a pressurised borehole. It can be shown that:

$$
\frac{R_{d}}{r_{h}}=25 \sqrt{\frac{P_{\text {ewall }}}{1300}}
$$

where:

$P_{\text {ewall }}=$ the borehole wall pressure for the explosive.

$1300=$ borehole wall pressure for a fully-coupled charge of ANFO $\left(\rho_{A N F O}=0.85 \mathrm{~g} / \mathrm{cm}^{3}\right.$ and $\mathrm{VOD}=3,500 \mathrm{~m} / \mathrm{s}$ ).

The explosive wall pressure is general and applies both for fully-coupled and de-coupled charges. For the case of de-coupled charges, the co-volume approach described in Appendix 1 is used to calculate the wall pressure. It is noted that Equation (10) does not include any dependence on the rock mass. To address this, at least in part, the same density dependence obtained in developing the energy approach has been arbitrarily included. The final equation becomes:

$$
\frac{R_{d}}{r_{h}}=25 \sqrt{\frac{P_{\text {ewall }}}{1300}} \sqrt{\frac{2.65}{\rho_{\text {rock }}}}
$$

This seems to better reflect the effect of explosive 'heaviness (bulk strength)' on the $R_{d} / r_{h}$ factor as described by Ash (1963) than does the energy approach. However, it is clear that other approaches should be considered. Figure 26 is a simple design curve relating $R_{d} / r_{h}$ to the wall pressure for rock of density, where $\rho_{\text {rock }}=2.65 \mathrm{~g} / \mathrm{cm}^{3}$.

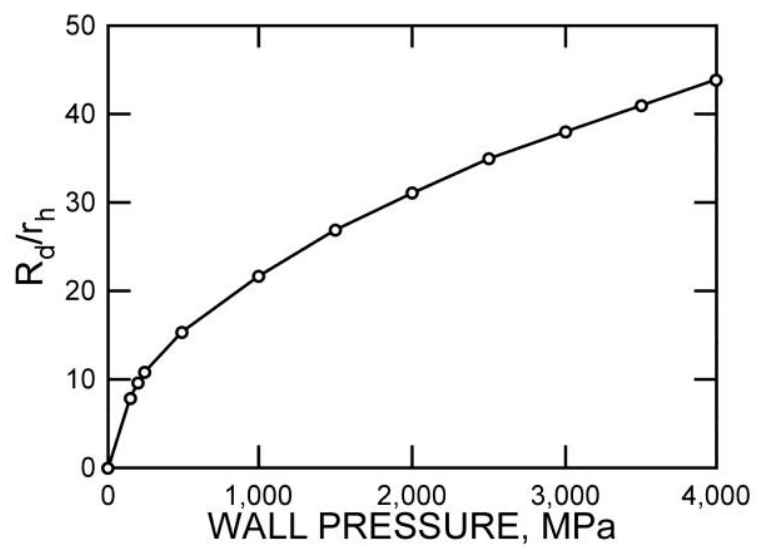

Figure 26 Plot of $R_{d} / r_{h}$ versus wall pressure for the Modified Ash Energy-based Approach

\subsection{The Holmberg Explosive Factor Approach}

Holmberg (1982) in his paper "Charge Calculations for Tunnelling", presented the following formula based on work done by Langefors and Kihlström (1963) for use when designing the burdens for the lifter and stoping holes:

$$
V=0.9 \sqrt{\frac{l s_{A N F O}}{(c+0.05) f(E / V)}}
$$

where:

$V \quad=\quad$ burden $(\mathrm{m})=$ distance from the charge to the free surface.

$l=\quad$ charge concentration $(\mathrm{kg} / \mathrm{m})$.

$s_{A N F O}=\quad$ weight strength of the explosive with respect to ANFO. 
$c=$ rock constant $\left(\mathrm{kg} / \mathrm{m}^{3}\right)=0.4 \mathrm{~kg} / \mathrm{m}^{3}$ for typical Swedish granite.

$f \quad=\quad$ fixation factor (dimensionless) which refers to the degree of hole confinement.

$E \quad=\quad$ hole spacing $(\mathrm{m})$.

It is an explosive energy based relationship originally developed by Langefors and Kihlström (1963).

The approach is based on the geometrical idea that the burden is the distance between the line of holes and the free surface. It does not take into account the idea that the damage from the explosive extends outward from the hole in all directions. If one considers this type of breakage model, it is possible to rewrite the burden formula given, Equation (12), in a form consistent with some of the other damage radius approaches - for example, the Modified Ash Energy-based Approach.

Assuming a circle of damage of radius $\mathrm{R}_{\mathrm{d}}$, and a just-touching design, then:

$V \quad=2 R_{d}$

$E / V \quad=1$.

Equation (12) becomes:

$$
2 R_{d}=0.9 \sqrt{\frac{l s_{A N F O}}{(c+0.05) f(1)}}
$$

The charge concentration per metre, 1 , can be written as:

$$
l=\frac{\pi}{4} d_{e}^{2} \rho_{e}
$$

where:

$d_{e} \quad=\quad$ explosive diameter $(\mathrm{m})$.

$\rho_{e} \quad=\quad$ explosive density $\left(\mathrm{kg} / \mathrm{m}^{3}\right)$.

It is convenient to write Equation (14) as:

$$
l=\frac{\pi}{4} d_{e}^{2} \rho_{e}\left(\frac{d_{h}}{d_{h}}\right)^{2}=\frac{\pi}{4} d_{h}^{2} \rho_{e}\left(\frac{d_{e}}{d_{h}}\right)^{2}
$$

where:

$d_{h} \quad=\quad$ hole diameter.

Substituting Equation (15) into Equation (13) yields:

$$
2 R_{d}=0.9 \sqrt{\frac{\pi}{4}\left(\frac{d_{e}}{d_{h}}\right)^{2} \frac{d_{h}^{2} \rho_{e} s_{A N F O}}{(c+0.05) f(1)}}
$$

simplifying Equation (16) yields:

$$
2 R_{d}=0.9 d_{h} \sqrt{\frac{\pi}{4}}\left(\frac{d_{e}}{d_{h}}\right) \sqrt{\frac{\rho_{e} s_{A N F O}}{(c+0.05) f(1)}}=0.8 d_{h}\left(\frac{d_{e}}{d_{h}}\right) \sqrt{\frac{\rho_{e} s_{A N F O}}{(c+0.05) f}}
$$

since:

$d_{h} \quad=2 r_{h}$.

Equation (17) becomes:

$$
\frac{R_{d}}{r_{h}}=0.8\left(\frac{d_{e}}{d_{h}}\right) \sqrt{\frac{\rho_{e} s_{A N F O}}{(c+0.05) f}}
$$


For the case of ANFO with density $850 \mathrm{~kg} / \mathrm{m}^{3}$ completely filling the hole in typical Swedish granite $\left(c=0.4 \mathrm{~kg} / \mathrm{m}^{3}\right)$ with a fixation factor $f=1$, one finds that:

$$
\frac{R_{d}}{r_{h}}=0.8(1) \sqrt{\frac{850(1)}{(0.4+0.05)(1)}}=34.8
$$

as indicated earlier, the Modified Ash Energy-based Approach can be written as:

$$
\frac{R_{d}}{r_{h}}=25\left(\frac{d_{e}}{d_{h}}\right) \sqrt{\frac{\rho_{e} s_{A N F O}}{\rho_{\text {ANFO }}}} \sqrt{\frac{2.65}{\rho_{\text {rock }}}}
$$

substituting the appropriate values, one finds that:

$$
\frac{R_{d}}{r_{h}}=25
$$

There is clearly a significant difference between the results obtained using the Holmberg Approach and the Modified Ash Energy-based Approach. In trying to understand the difference, one must examine the rock constant term, $c+0.05$, which is likened to the normal explosive factor (EF). The term "explosive factor" has been used here rather than the more commonly used "powder factor" since the former includes reference to the explosive being used. When using ANFO in normal drifting, the explosive factor, $E F_{t}$, for the stoping holes would typically be of the order of:

$$
E F_{t}=0.25-0.35 \mathrm{~kg} / \mathrm{t}
$$

The subscript " $t$ " refers to the fact that it is a tonnage based explosive factor. For rock with a density of $2.65 \mathrm{t} / \mathrm{m}^{3}$, this corresponds to:

$$
E F_{v}=0.7-0.9 \mathrm{~kg} / \mathrm{m}^{3}
$$

The subscript " $v$ " indicates that it is a volume based explosive factor. One can see that this is of the order of 1.5-2 times the rock constant factor (0.45) suggested for use. Returning to Equation (19) and applying this range of practical rock constant factors one finds that:

$$
\frac{R_{d}}{r_{h}}=0.8(1) \sqrt{\frac{850(1)}{(0.7 \rightarrow 0.9)(1)}}=27.9 \rightarrow 24.6
$$

This is the same order of magnitude used in the Modified Ash Energy-based Approach. The so-modified Holmberg formula which will be termed the "Holmberg Explosive Factor Approach," becomes:

$$
\frac{R_{d}}{r_{h}}=0.8\left(\frac{d_{e}}{d_{h}}\right) \sqrt{\frac{\rho_{e} s_{A N F O}}{E F_{v}(f)}}
$$

It appears to provide reasonable values when using $\mathrm{EF}_{\mathrm{v}}$ in place of the rock constant. For the special case when the rock density is $2.65 \mathrm{~kg} / \mathrm{m}^{3}$, Equation (20) can be re-written in the form:

$$
\frac{R_{d}}{r_{h}}=0.8\left(\frac{d_{e}}{d_{h}}\right)\left(\frac{\sqrt{850}}{\sqrt{2.65}}\right) \sqrt{\frac{\rho_{e} s_{A N F O}}{\rho_{A N F O} E F_{t}(f)}}=14.3\left(\frac{d_{e}}{d_{h}}\right) \sqrt{\frac{R B S}{E F_{t}(f)}}
$$

where:

$E F_{t} \quad=\quad$ kilograms of the given explosive/tonne.

Design curves are given in Figure 27 for the case when the fixation factor $f=1$ and the charge is fullycoupled. 


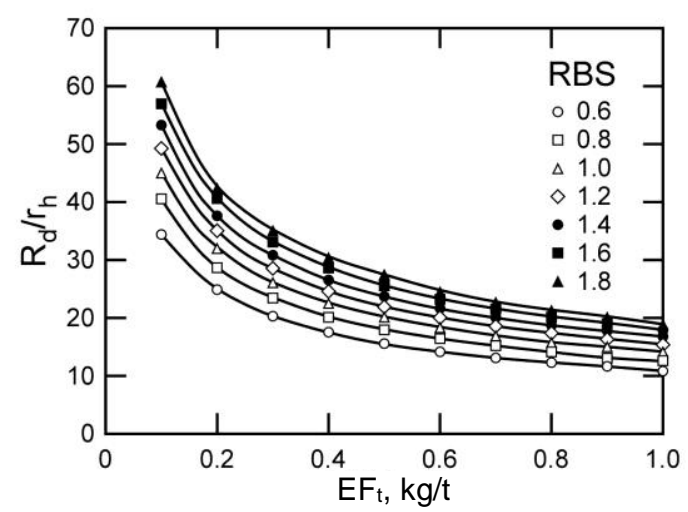

Figure 27 Plot of $\boldsymbol{R}_{d} / r_{h}$ versus $E F_{t}$ for the Holmberg Explosive Factor Approach

\subsection{The Neiman Hydrodynamic Approach}

Neiman (1979, 1984a, 1984b, 1986a, 1986b) examined the problem of the detonation of a cylindrical explosive charge in a rock mass based on the application of principles from hydrodynamics. In his approach, the following assumptions are made:

- charge detonation takes place in a confined space

- as a result of detonation, the explosive charge of given size and shape is instantaneously transformed into a volume of gaseous products of the same size and shape

- in dense, monolithic rocks of high specific gravity and high ultimate rupture strength, the gaseous products do not substantially modify the properties of the rock prior to the completion of the detonation process

- after detonation it is assumed that some average pressure is established in the borehole

- the medium surrounding the charge is considered to be linearly elastic and incompressible. No account is taken of rock microstructure, fracturability, strength, or other properties

- the medium is considered isotropic with respect to all properties

- the effect of the shock wave is neglected

- irreversible processes can only occur in the rock after the condition for plasticity is attained.

The velocity field is determined assuming that all of the explosive energy is transferred to the rock medium. The size of the zone of destruction is obtained by examining the peak particle velocity contours. In the actual rock fragmentation process, the assumption of incompressibility is inappropriate. Actual site behaviour can be included through a calibration process. This process has been discussed by Tesarik and Hustrulid (2009).

Neiman (1979) obtained the following equations for the velocity oriented at right angles to the charge axis and located along charge mid-length:

$$
V_{h}=\frac{1}{\rho} \sqrt{\frac{\rho_{e q} q}{8 \rho_{r}}}
$$

where:

$\begin{array}{lll}\rho_{e q} & = & \text { equivalent explosive density }\left(\mathrm{kg} / \mathrm{m}^{3}\right) . \\ \rho_{r} & = & \text { density of the rock }\left(\mathrm{kg} / \mathrm{m}^{3}\right) . \\ q & = & \begin{array}{l}\text { explosive energy/unit mass }\left(\text { expressed in } \mathrm{m}^{2} / \mathrm{s}^{2}\right) . \text { This is obtained using the explosive } \\ \text { energy expressed in } \mathrm{kcal} / \mathrm{kg} \text { and multiplying by the conversion factor of } 4,190 .\end{array} \\ V_{h} & = & \text { velocity }(\mathrm{m} / \mathrm{s}) .\end{array}$




$$
\begin{gathered}
\rho=\frac{\bar{r} \sqrt{v_{s}} \sqrt{(\bar{r})^{2}+\frac{\bar{L}^{2}}{4}}}{\bar{L}} \\
v_{s}=\ln \frac{\bar{L}+\sqrt{1+\bar{L}^{2}}}{-\bar{L}+\sqrt{1+\bar{L}^{2}}} \\
\bar{L}=\frac{L}{d} \\
\bar{r}=\frac{R}{d}
\end{gathered}
$$

where:

$$
\begin{array}{lll}
R & = & \text { distance from the charge axis }(\mathrm{m}) . \\
L & = & \text { charge length. } \\
d & = & \text { hole diameter. }
\end{array}
$$

As can be seen, all of the geometric parameters are contained in the term $1 / \rho$. Although the effect of de-coupled charges was not addressed by Neiman (1986a), it appears that this can be included by modifying Equation (22) to:

$$
V_{h}=\frac{1}{\rho}\left(\frac{d_{e}}{d_{h}}\right) \sqrt{\frac{\rho_{e} q}{8 \rho_{r}}}
$$

where:

$\begin{array}{lll}\rho_{e} & = & \text { explosive density. } \\ d_{e} & = & \text { explosive diameter. } \\ d_{h} & = & \text { hole diameter. }\end{array}$

To demonstrate the application it will be assumed that the explosive is ANFO (fully-coupled) with:

$$
\begin{array}{lll}
Q & = & 890 \mathrm{kcal} / \mathrm{kg} . \\
\rho_{e} & = & 950 \mathrm{~kg} / \mathrm{m}^{3} .
\end{array}
$$

In addition,

$d_{h} \quad=\quad$ variable: $0.038 \mathrm{~m}, 0.048 \mathrm{~m}, 0.064 \mathrm{~m}$.

$L \quad=4 \mathrm{~m}$.

rock is granite with $\rho_{r}=2,650 \mathrm{~kg} / \mathrm{m}^{3}$.

The ANFO density of $0.95 \mathrm{~g} / \mathrm{cm}^{3}$ chosen in this case is what would result if the ANFO were blown into the hole using a compressed air powered pot. The theoretical particle velocity as a function of the distance, $R$, away from the centre of the charge is plotted in Figure 28 for the three hole diameters. The actual velocitydistance curves would be somewhat different from the ones plotted due to the fact that actual rock masses are not incompressible, etc. This means that the actual velocities would be lower. However, the lack of site calibration does not preclude use of the curves. 


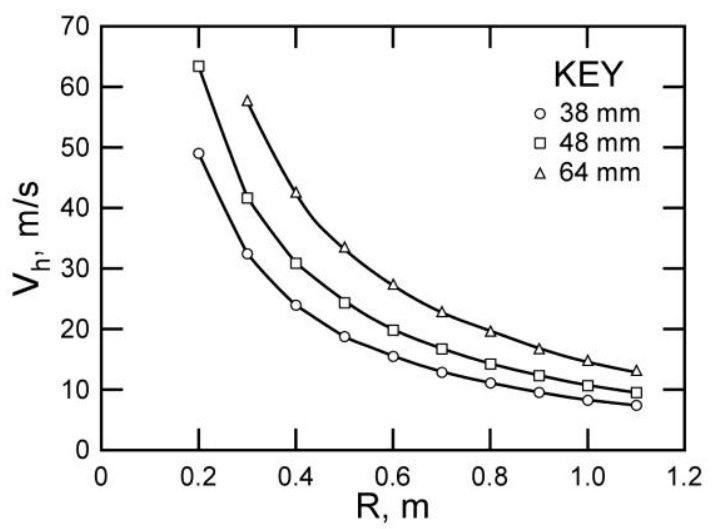

Figure 28 Particle velocity as a function of distance with hole diameter as the parameter

It will be observed that these curves are similar in form and use to those originally presented in 1979 by Holmberg and Persson (1979), which have been widely used for design. Unfortunately, some mathematical mistakes were recently discovered in the development of the Holmberg-Persson curves (Hustrulid and Lu, 2002) and that is why the approach has not been included here.

To be able to use these curves for design, one must know the velocity corresponding to the damage radius limit. This can be obtained in several ways. The first is to make observations in the mine. One would determine the damage radius corresponding to a particular charge/explosive configuration. One then begins at this position on the $\mathrm{x}$-axis of the plot, moves vertically to the appropriate curve and then moves horizontally to the y-axis and reads the corresponding velocity. This value would then be used when evaluating different design possibilities. A second approach is to estimate the critical velocity corresponding to the compressive strength limit using:

$$
V_{h}=c \frac{\sigma_{c}}{E}
$$

where:

$$
\begin{array}{lll}
c & = & \text { P-wave velocity }(\mathrm{m} / \mathrm{s}) . \\
\sigma_{c} & = & \text { compressive strength }(\mathrm{MPa}) . \\
E & = & \text { Young's modulus }(\mathrm{MPa}) .
\end{array}
$$

This approach will be discussed in Section 5 .

\subsection{The Sher Quasi-Static Approach}

Sher and co-workers (Sher, 1997; Sher and Aleksandrova, 1997, 2007) have written a series of papers concerning the development of the damage zones surround a cylindrical charge. It is a pressure based approach and assumes that the charge is fully-coupled. Although both dynamic and quasi-static approaches have been developed, in this paper the quasi-static approach is included. For derivation details, the interested reader is referred to the papers included in the references or to a forthcoming paper by NIOSH. Here, simply the relevant equations will be presented and their application demonstrated.

The basic equations are:

$$
\begin{gathered}
\left(\frac{Y}{\alpha}-q\right)\left(\frac{b}{a}\right)^{\alpha /(1+\alpha)}-\frac{Y}{\alpha}-p(a)=0 \\
q=-\frac{Y_{2}+2 P\left(1+\alpha_{2}\right)}{2+\alpha_{2}}
\end{gathered}
$$




$$
\begin{gathered}
u_{b}=-\frac{(1+v) b[q+2 P(1-v)]}{E} \\
a^{2}-a_{o}^{2}=b^{2}-\left(b-u_{b}\right)^{2}
\end{gathered}
$$

where:

$$
\begin{array}{ll}
\alpha & =\frac{2 \sin \phi}{1-\sin \phi} . \\
Y & =\frac{2 c \cos \phi}{1-\sin \phi} . \\
\alpha_{2} & =\frac{\sigma_{c}}{\sigma_{t}}-1 . \\
Y_{2} & =\sigma_{c} . \\
c & =\text { cohesion (MPa). } \\
\varphi & =\text { angle of internal friction (degrees). } \\
E & =\text { Young's modulus (MPa). } \\
v & =\text { Poisson's ratio. } \\
\sigma_{c} & =\text { compressive strength (MPa). } \\
\sigma_{t} & =\text { in situ stress (MPa). } \\
p(a) & \text { initial radius of hole }=\text { charge radius (m). } \\
P & =\text { final hole radius (m). } \\
a_{o} & =\text { final outer radius of the crushed zone (m). } \\
a & =\text { external pressure (in situ stress), m. } \\
b & =
\end{array}
$$

The gas pressure in the cavity is determined on the basis of the Jones-Miller adiabatic curve given in Equations (33) and (34):

$$
\begin{gathered}
p(a)=P_{o}\left(\frac{a}{a_{o}}\right)^{-2 \gamma_{1}}, a \leq a * \\
p(a)=P_{o}\left(\frac{a^{*}}{a_{o}}\right)^{-2 \gamma_{1}}\left(\frac{a}{a^{*}}\right)^{-2 \gamma_{2}}, a \geq a^{*}
\end{gathered}
$$

where:

$P_{o} \quad=\quad$ initial wall pressure due to the explosion.

$\gamma_{1}=$ initial adiabatic expansion constant $=3$.

$\gamma_{2}=$ final adiabatic expansion constant $=1.27$.

$a^{*} / a=$ radius ratio at the change in constant occurs $=1.89$.

$a^{*} \quad=\quad$ radius at which the adiabatic constant changes. 
It is advantageous to normalise Equations (29), (30) and (33) by the modulus $E$, this has been done below. Equation (29) becomes:

$$
\left(\frac{Y}{E \alpha}-\frac{q}{E}\right)\left(\frac{b}{a}\right)^{\alpha /(1+\alpha)}-\frac{Y}{E \alpha}-\frac{p(a)}{E}=0
$$

Equation (30) becomes:

$$
\frac{q}{E}=-\frac{\frac{Y_{2}}{E}+2 \frac{P}{E}\left(1+\alpha_{2}\right)}{2+\alpha_{2}}
$$

Equations (33) and (34) become:

$$
\frac{p(a)}{E}=\frac{P_{o}}{E}\left(\frac{a}{a_{o}}\right)^{-2 \gamma_{1}} \quad, a \leq a^{*}
$$

and

$$
\frac{p(a)}{E}=\frac{P_{o}}{E}\left(\frac{a^{*}}{a_{o}}\right)^{-2 \gamma_{1}}\left(\frac{a}{a^{*}}\right)^{-2 \gamma_{2}}, a \geq a^{*}
$$

The remaining equations are normalised with respect to $a_{o}$. Equation (31) becomes:

$$
\frac{u_{b}}{a_{o}}=-(1+v) \frac{b}{a_{o}} \frac{[q+2 P(1-v)])}{E}
$$

and Equation (32) becomes:

$$
\left(\frac{a}{a_{o}}\right)^{2}-1=\left(\frac{b}{a_{o}}\right)^{2}-\left[\frac{b}{a_{o}}-\frac{u_{b}}{a_{o}}\right]^{2}
$$

Thus, these normalised equations (Equations (35)-(39)) are used in the calculations, and the following calculation procedure is used:

1. One begins with Equation (36) and calculates $q / E$.

2. One now makes a guess of $b / a_{o}$.

3. This guess, together with $q / E$, are substituted into Equation (38). One calculates $u_{b} / a_{o}$.

4. This result is substituted into Equation (39) and one calculates $a / a_{o}$.

5. The value of $a / a_{o}$ is compared with $a * / a_{o}=1.89$. Based upon this, one chooses the appropriate pressure Equation (37a) or (37b). One obtains $p(a) / E$.

6. This value is then substituted into Equation (35) and you examine whether the equality is achieved. If the answer is yes, you are done. If not, one goes back to step 2 and another $b / a_{o}$ is guessed.

This procedure is handled very easily using a spreadsheet. It will be assumed that ANFO with density $850 \mathrm{~kg} / \mathrm{m}^{3}$ and $\mathrm{VOD}=3,500 \mathrm{~m} / \mathrm{s}$ is used. The explosion pressure is calculated using:

$$
P_{o}=\frac{1}{8} \rho_{A N F O}(V O D)^{2}=\frac{1}{8} 850(3.5)^{2}=1300 M P a
$$

It is assumed that the borehole is infinite in length and:

$$
a_{o}=0.048 \mathrm{~m}(48 \mathrm{~mm})
$$

The granitic rock has the following properties:

density $=2,650 \mathrm{~kg} / \mathrm{m}^{3}$. 


$\begin{array}{lll}E & = & 86,000 \mathrm{MPa} . \\ v & = & 0.25 . \\ \sigma_{c} & = & 172 \mathrm{MPa}=Y_{2} . \\ c & = & 24.8 \mathrm{MPa} . \\ \sigma_{c} / \sigma_{t} & = & 6 . \\ \varphi & = & 55^{\circ} . \\ P & = & 0 \text { (in situ stress). } \\ P_{o} & = & 1,300 \mathrm{MPa} .\end{array}$

Substituting these values into the Sher equations, one finds that:

$$
\frac{b}{a_{o}}=\frac{R_{d}}{r_{h}}=25
$$

To be consistent with the other approaches, it is desired to present a simple set of design curves. As can be seen, there are a number of different input parameters involved and so some decisions have been taken to obtain a more or less representative set of values. The following were selected:

$$
\begin{array}{llll}
\frac{\sigma_{c}}{c} & = & 5 . \\
\frac{E}{\sigma_{c}} & = & 300 . \\
\frac{\sigma_{c}}{\sigma_{t}} & = & 12 . \\
\varphi & = & 41.84^{\circ} . \\
v & =0.3 . \\
a_{o} & = & r_{h}=0.0225 \mathrm{~m} . \\
\rho_{r} & = & 2,650 \mathrm{~kg} / \mathrm{m}^{3} . \\
P & = & \text { in situ stress }=0 .
\end{array}
$$

The ratio:

$$
\frac{R_{d}}{r_{h}}=\frac{b}{a_{o}}
$$

was determined for different combinations of the rock compressive strength $\left(\sigma_{\mathrm{c}}\right)$ and the explosive pressure $\left(P_{o}\right)$. Figure 29 presents the results.

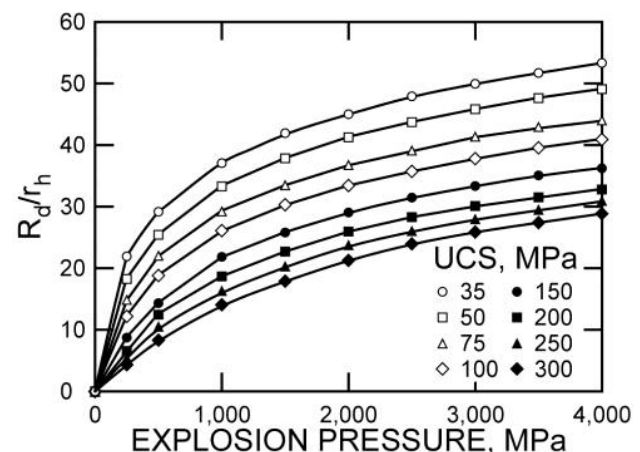

Figure 29 The design charts when using the Sher Quasi-Static Approach 
It can be seen the results are generally consistent with those produced using the other approaches. An advantage with the Sher Quasi-Static Approach is that different rock parameters can be specifically included. This is also a disadvantage if they are not available.

\section{Application of the approach to the evaluation of an actual blast design}

\subsection{Example}

Figure 30 shows an actual blast design which has performed satisfactorily. It will serve as the basis for analysis using the NIOSH damage radius approach. The round is drilled using an Atlas Copco computercontrolled drill jumbo. The round is charged using site sensitised emulsion (SSE). The charging rig has string loading capability which was used in charging the perimeter holes.

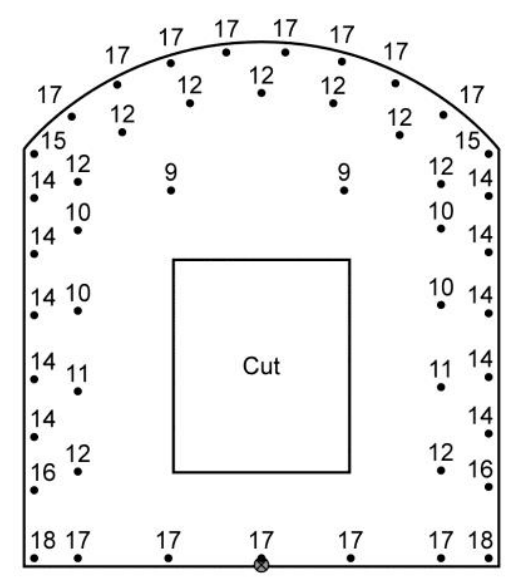

Figure 30 The blast design used as an example

The following parameters are used in the calculations:

\subsubsection{Rock properties}

- Volcanic rock type: monzonite.

- Density: $2.8 \mathrm{~g} / \mathrm{cm}^{3}$.

- Young's modulus: 72,000 MPa.

- Poisson's ratio: 0.28.

- P-wave velocity: $5,900 \mathrm{~m} / \mathrm{s}$.

- Unconfined compressive strength: $150 \mathrm{MPa}$.

- Tensile strength: $22 \mathrm{MPa}$ (Brazilian test).

- Friction angle $=45^{\circ}$.

\subsubsection{Explosive properties}

- Type: SSE.

- Energy: $3.1 \mathrm{MJ} / \mathrm{kg}=740 \mathrm{kcal} / \mathrm{kg}$.

- Gas volume: about 950 1/kg.

- Density: $0.85 \mathrm{~g} / \mathrm{cm}^{3}$.

- VOD: $4,300 \mathrm{~m} / \mathrm{s}$.

- Relative weight strength (RWS): $s_{A N F O}=0.84$. 
- Easer/buffer/reliever holes: fully charged.

- Perimeter holes: string loaded to $50 \%$ of hole cross-sectional area.

- Adiabatic constant assumed: $\gamma=3.0$.

\subsubsection{Geometry}

- Hole diameter: $48 \mathrm{~mm}$.

- Hole length: $6 \mathrm{~m}$.

- Drift width: $5.5 \mathrm{~m}$.

- Drift height (shoulder): $4.8 \mathrm{~m}$.

- Drift height (crown): $6 \mathrm{~m}$.

- Drift cross-sectional area: $31 \mathrm{~m}^{2}$.

The different methods described for determining the damage radius will be demonstrated for both the fully-coupled holes and the perimeter holes.

\subsection{Damage radius for the easer holes}

\subsubsection{The Modified Ash Pressure-based Approach}

The basic equation is:

$$
\frac{R_{d}}{r_{h}}=25 \sqrt{\frac{P_{e}}{P_{\text {ANFO }}}} \sqrt{\frac{2.65}{\rho_{\text {rock }}}}
$$

it will be assumed that the explosion pressure $P_{e}$ is calculated using:

$$
P_{e}=\frac{1}{8} \rho_{e}(V O D)^{2}
$$

where:

$\rho_{e} \quad=\quad 850 \mathrm{~kg} / \mathrm{m}^{3}$.

$V O D=4.3 \mathrm{~km} / \mathrm{s}$.

Thus,

$$
P_{e}=\frac{1}{8} \rho_{e}(V O D)^{2}=\frac{1}{8}(850)(4.3)^{2}=1965 M P a
$$

using $P_{A N F O}=1,300 \mathrm{MPa}$ and $\rho_{r}=2.8 \mathrm{~g} / \mathrm{cm}^{3}$, one finds that:

$$
\frac{R_{d}}{r_{h}}=25 \sqrt{\frac{P_{\text {exp }}}{P_{\text {ANFO }}}} \sqrt{\frac{2.65}{\rho_{\text {rock }}}}=25 \sqrt{\frac{1965}{1300}} \sqrt{\frac{2.65}{2.8}}=29.9
$$

the damage radius then becomes:

$$
R_{d}=29.9(0.024)=0.72 \mathrm{~m}
$$

\subsubsection{The Modified Ash Energy-based Approach}

The basic equation is:

$$
\frac{R_{d}}{r_{h}}=25 \sqrt{\frac{\rho_{e} s_{A N F O}}{\rho_{\text {ANFO }}}} \sqrt{\frac{2.65}{\rho_{\text {rock }}}}=25 \sqrt{\frac{0.85(0.84)}{0.85}} \sqrt{\frac{2.65}{2.8}}=25(0.92)(0.97)=22.3
$$


the damage radius then becomes:

$$
R_{d}=22.2(0.024)=0.53 m
$$

\subsubsection{The Holmberg Explosive Factor Approach}

The basic equation is:

$$
\frac{R_{d}}{r_{h}}=0.8\left(\frac{d_{e}}{d_{h}}\right) \sqrt{\frac{\rho_{e} s_{A N F O}}{E F_{v_{A N F O}}}}
$$

assuming that the fixation factor is 1 . In this case, the hole is filled with explosive and the explosive diameter $\left(d_{e}\right)$ is equal to the hole diameter $\left(d_{h}\right)$. The density of the explosive $\left(\rho_{e}\right)$ is $850 \mathrm{~kg} / \mathrm{m}^{3}$ and the relative weight strength $\left(s_{A N F O}\right)$ is 0.84 . Thus,

$$
\frac{R_{d}}{r_{h}}=0.8 \sqrt{\frac{\rho_{e} s_{A N F O}}{E F_{A N F O}}}=0.8 \sqrt{\frac{850(0.84)}{E F_{A N F O}}}=0.8 \sqrt{\frac{714}{E F_{A N F O}}}
$$

the ANFO equivalent explosives factor $\left(E F_{V A N F O}\right)$ is not known in this particular case. Assuming an average value of $0.8 \mathrm{~kg} / \mathrm{m}^{3}$ which is appropriate for hard rock one finds:

$$
\frac{R_{d}}{r_{h}}=0.8 \sqrt{\frac{714}{E F_{A N F O}}}=0.8 \sqrt{\frac{714}{0.8}}=24
$$

the damage radius then becomes:

$$
R_{d}=24(0.024)=0.58 \mathrm{~m}
$$

\subsubsection{The Neiman Hydrodynamic Approach}

The basic equation is:

$$
V_{h}=\frac{1}{\rho} \sqrt{\frac{\rho_{e} q}{8 \rho_{r}}}=\frac{1}{\rho} I
$$

where:

$$
\begin{aligned}
V_{h} & =\text { velocity }(\mathrm{m} / \mathrm{s}) . \\
I & =\sqrt{\frac{\rho_{e} q}{8 \rho_{r}}} . \\
\rho & =\frac{\bar{r} \sqrt{v_{s}} \sqrt{(\bar{r})^{2}+\frac{\bar{L}^{2}}{4}}}{\bar{L}} . \\
v_{s} & =\frac{\ln \frac{\bar{L}+\sqrt{1+\bar{L}^{2}}}{-\bar{L}+\sqrt{1+\bar{L}^{2}}} .}{\bar{L}} \quad \\
\bar{r} & =\frac{L}{d} \cdot \\
R & =\text { distance from the charge axis (m). } \\
L & =\text { charge length (m). }
\end{aligned}
$$


$d \quad=\quad$ hole diameter $(\mathrm{m})$.

In this case, the constant factor becomes:

$$
I=\sqrt{\frac{\rho_{e} q}{8 \rho_{r}}}=\sqrt{\frac{0.85(740)(4190)}{8(2.8)}}=343 \mathrm{~m} / \mathrm{s}
$$

the factor 4,190 has been introduced to convert the explosive energy $(q)$ expressed in $\mathrm{kcal} / \mathrm{kg}$ to the desired units of $\mathrm{m}^{2} / \mathrm{s}^{2}$. Based on the geometry, one obtains the following:

$$
\begin{gathered}
\bar{L}=\frac{L}{d}=\frac{6}{0.048}=125 \\
v_{s}=\ln \frac{\bar{L}+\sqrt{1+\bar{L}^{2}}}{-\bar{L}+\sqrt{1+\bar{L}^{2}}}=\ln \frac{125+\sqrt{1+125^{2}}}{-125+\sqrt{1+125^{2}}}=11.04 \\
\bar{r}=\frac{R}{d}=\frac{R}{0.048}
\end{gathered}
$$

hence,

$$
\rho=\frac{\bar{r} \sqrt{v_{s}} \sqrt{(\bar{r})^{2}+\frac{\overline{L^{2}}}{4}}}{\bar{L}}=\frac{\frac{R}{0.048} \sqrt{11.04} \sqrt{\left(\frac{R}{0.048}\right)^{2}+\frac{125^{2}}{4}}}{125}
$$

and

$$
\rho=\frac{\frac{R}{0.048} \sqrt{11.04} \sqrt{\left(\frac{R}{0.048}\right)^{2}+\frac{125^{2}}{4}}}{125}=\frac{69.22 R \sqrt{434 R^{2}+3906}}{125}
$$

finally,

$$
V_{h}=343\left[\frac{125}{69.22 R \sqrt{434 R^{2}+3906}}\right]=\frac{619}{R \sqrt{434 R^{2}+3906}}
$$

the plot of velocity $V_{h}$ versus the distance $R$ is shown in Figure 31 .

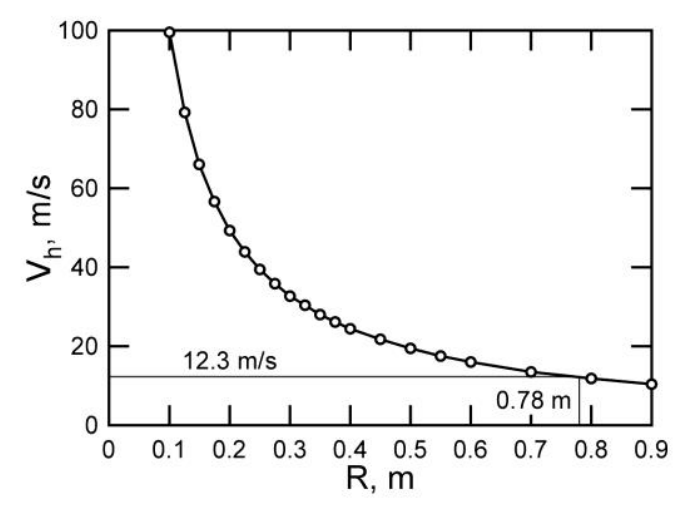

Figure 31 Plot of the particle velocity $V_{h}$ versus the distance, $R$ 
As indicated earlier, the damage radius is thought to coincide with the compressive strength limit. The following estimation for the limiting particle velocity will be used:

$$
V_{p}=c \varepsilon=c \frac{\sigma_{c}}{E}
$$

substituting the appropriate values, one finds that:

$$
V_{p}=c \varepsilon=c \frac{\sigma_{c}}{E}=5900\left(\frac{150}{72000}\right)=12.3 \mathrm{~m} / \mathrm{s}
$$

superimposing this value on Figure 31, one finds that the corresponding damage radius $R_{d}$ is:

$R_{d} \quad=\quad 0.8 \mathrm{~m}$.

this corresponds to:

$R_{d} / r_{h} \quad=\quad 33$.

as was indicated earlier, this is the maximum expected value since an in situ calibration was not performed.

\subsubsection{The Sher Quasi-Static Approach}

As indicated, this is the most complicated of the approaches presented and a spreadsheet is used for making the calculations. The cohesion $(c)$ of the rock has not been given and it will be assumed that it is:

$$
c=\frac{\sigma_{c}}{5}=\frac{150}{5}=30 \mathrm{MPa}
$$

it is also assumed that the effect of the in situ stress $(P)$ can be neglected. Indicated by the following equations are the values for the different ratios and parameters used in the solution:

$$
\begin{gathered}
\alpha=\frac{2 \sin \phi}{1-\sin \phi}=\frac{2 \sin \left(45^{\circ}\right)}{1-\sin \left(45^{\circ}\right)}=4.828 \\
Y=\frac{2 c \cos \phi}{1-\sin \phi}=\frac{2(30) \cos \left(45^{\circ}\right)}{1-\sin \left(45^{\circ}\right)}=145 \mathrm{MPa} \\
\alpha_{2}=\frac{\sigma_{c}}{\sigma_{t}}-1=\frac{150}{22}-1=6 \\
Y_{2}=\sigma_{c}=150 \mathrm{MPa} \\
\frac{Y_{2}}{E}=\frac{150}{72000}=0.00208 \\
\frac{Y}{E}=\frac{145}{72000}=0.00201 \\
\frac{P_{o}}{E}=\frac{1965}{72000}=0.0273
\end{gathered}
$$

these values are substituted into the appropriate equations and then one assumes different ratios of $b / a_{o}$ (the damage radius/hole radius). The ratio of $b / a_{o}$ which satisfies the system of equations is selected. In this particular case, it is found that:

$$
\frac{R_{d}}{r_{h}}=\frac{b}{a_{o}}=28
$$


the damage radius then becomes:

$$
R_{d}=28(0.024)=0.67 \mathrm{~m}
$$

\subsubsection{Summary}

As might be expected, the different approaches yield somewhat different estimates of the damage radius. They are summarised in Table 1.

Table 1 Summary of the easer hole results

\begin{tabular}{lll}
\hline Approach & $\boldsymbol{R}_{\boldsymbol{d}} / \boldsymbol{r}_{\boldsymbol{h}}$ & $\boldsymbol{R}_{\boldsymbol{d}}(\boldsymbol{m})$ \\
\hline Modified Ash Pressure-based & 30 & 0.7 \\
Modified Ash Energy-based & 22 & 0.5 \\
Holmberg Explosive Factor & 24 & 0.6 \\
Neiman Hydrodynamic & $33(\max )$ & $0.8(\max )$ \\
Sher Quasi-Static & 28 & 0.7 \\
\hline
\end{tabular}

These results can be re-grouped depending upon whether they are explosive energy or explosive pressure based. This has been done in Table 2 .

Table 2 Easer hole results organised by energy and pressure techniques

\begin{tabular}{lll}
\hline Energy-based Approach & $\boldsymbol{R}_{d} / \boldsymbol{r}_{\boldsymbol{h}}$ & $\boldsymbol{R}_{\boldsymbol{d}}(\boldsymbol{m})$ \\
\hline Modified Ash Energy-based & 22 & 0.5 \\
Holmberg Explosive Factor & 24 & 0.6 \\
Neiman Hydrodynamic & $33(\max )$ & $0.8(\max )$ \\
\hline Pressure-based Approach & $\boldsymbol{R}_{d} / \boldsymbol{r}_{\boldsymbol{h}}$ & $\boldsymbol{R}_{\boldsymbol{d}}(\boldsymbol{m})$ \\
\hline Modified Ash Pressure-based & 30 & 0.7 \\
Sher Quasi-Static & 28 & 0.7 \\
\hline
\end{tabular}

In Figure 32, circles of radius $R_{d}$ equal to $0.6 \mathrm{~m}$ have been drawn around each of the reliever holes.

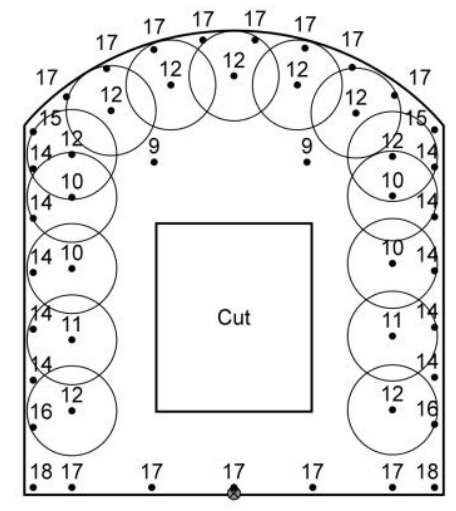

Figure 32 Damage circles superimposed over the easer holes

As can be seen, the circles extend just to the perimeter as should be the case. The amount of overlap is considered satisfactory. 


\subsection{Damage radius for the perimeter holes}

\subsubsection{Introduction}

String loading is used in the perimeter holes with about 50\% of the cross-sectional area filled with explosive. The equivalent explosive diameter $\left(d_{e}\right)$ is determined using:

$$
\begin{aligned}
& \frac{\pi}{4} d_{e}^{2}=(0.50) \frac{\pi}{4} d_{h}^{2} \\
& d_{e}=d_{h} \sqrt{0.5}=0.707 d_{h}=0.707(0.048)=0.034 \mathrm{~m}
\end{aligned}
$$

thus, the coupling $(C p l)$ is:

$$
C p l=\frac{d_{e}}{d_{h}}=\frac{0.034}{0.048}=0.71
$$

this common factor will appear in a number of the approaches.

\subsubsection{The Modified Ash Energy-based Approach}

The equation including the effect of de-coupled charges is:

$$
\frac{R_{d}}{r_{h}}=25\left(\frac{d_{e}}{d_{h}}\right) \sqrt{\frac{\rho_{e} s_{A N F O}}{\rho_{\text {ANFO }}}} \sqrt{\frac{2.65}{\rho_{\text {rock }}}}
$$

substituting the appropriate values, one obtains:

$$
\frac{R_{d}}{r_{h}}=25(0.71) \sqrt{\frac{0.85(0.84)}{0.85)}} \sqrt{\frac{2.65}{2.80}}=25(0.71)(0.92)(0.97)=15.8
$$

the expected damage radius is:

$$
R_{d}=15.8(0.024)=0.4 m
$$

\subsubsection{The Modified Ash Pressure-based Approach}

The appropriate equation is:

$$
\frac{R_{d}}{r_{h}}=25 \sqrt{\frac{P_{\text {ewall }}}{P_{\text {ANFO wall }}}} \sqrt{\frac{2.65}{\rho_{\text {rock }}}}
$$

it is necessary to determine the wall pressure for the de-coupled charge. The co-volume approach presented in Appendix 1 will be demonstrated here. The specific volume $\left(v_{e}\right)$ for the explosive is:

$$
v_{e}=\frac{1}{\rho_{e}}=\frac{1}{0.85}=1.176
$$

the volume term $\left(V_{e}\right)$ considering the co-volume correction is:

$$
V_{e}=v_{e}-1.1 e^{\frac{-0.473}{v_{e}}}=1.176-1.1 e^{\frac{-0.473}{1.176}}=1.176-0.736=0.440
$$

the specific volume for the explosive gases in the hole is:

$$
v_{h}=v_{e}\left(\frac{d_{h}}{d_{e}}\right)^{2}=1.176\left(\frac{0.048}{0.034}\right)^{2}=2.344
$$

the volume term $\left(V_{h}\right)$ considering the co-volume correction is: 


$$
V_{h}=v_{h}-1.1 e^{\frac{-0.473}{v_{h}}}=2.344-1.1 e^{\frac{-0.473}{2.344}}=2.344-0.899=1.445
$$

the wall pressure $\left(P_{e \text { wall }}\right)$ then becomes:

$$
P_{\text {ewall }}=P_{e}\left(\frac{V_{e}}{V_{h}}\right)=1965\left(\frac{0.440}{1.445}\right)=598 \mathrm{MPa}
$$

thus,

$$
\frac{R_{d}}{r_{h}}=25 \sqrt{\frac{P_{\text {ewall }}}{P_{\text {ANFO wall }}}} \sqrt{\frac{2.65}{\rho_{\text {rock }}}}=25 \sqrt{\frac{598}{1300}} \sqrt{\frac{2.65}{2.80}}=25(0.68)(0.97)=16.5
$$

the expected damage radius is:

$$
R_{d}=16.5(0.024)=0.4 \mathrm{~m}
$$

\subsubsection{The Holmberg Explosive Factor Approach}

The Holmberg equation expressed in a form to handle de-coupled charges is:

$$
\frac{R_{d}}{r_{h}}=0.8\left(\frac{d_{e}}{d_{h}}\right) \sqrt{\frac{\rho_{e} s_{A N F O}}{E F_{v}}}
$$

assuming an explosive factor $\left(E F_{v}\right)$ of $0.8 \mathrm{~kg} / \mathrm{m}^{3}$ and the other factors as included earlier, one obtains:

$$
\frac{R_{d}}{r_{h}}=0.8\left(\frac{d_{e}}{d_{h}}\right) \sqrt{\frac{\rho_{e} s_{A N F O}}{E F_{v}}}=0.8\left(\frac{0.034}{0.048}\right) \sqrt{\frac{850(0.84)}{0.8}}=16.9
$$

the expected damage radius is:

$$
R_{d}=16.9(0.024)=0.41 \mathrm{~m}
$$

\subsubsection{The Neiman Hydrodynamic Approach}

The Neiman equation expressed in a form to handle de-coupled charges is:

$$
V_{h}=\frac{1}{\rho}\left(\frac{d_{e}}{d_{h}}\right) I=\frac{1}{\rho} I^{\prime}
$$

the new constant term $\left(I^{\prime}\right)$ becomes:

$$
I^{\prime}=\left(\frac{d_{e}}{d_{h}}\right) I=\left(\frac{0.034}{0.048}\right)(343)=243 \mathrm{~m} / \mathrm{s}
$$

the plot of $V_{h}$ versus $R$ is shown in Figure 33 . 


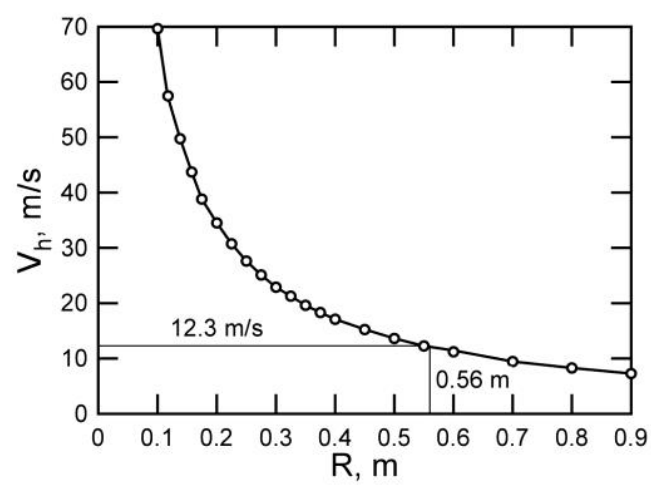

Figure 33 Plot of $V_{h}$ versus the distance $R$ for the string loaded perimeter holes

Using the same damage criterion as determined earlier for the easer holes $\left(V_{h}=12.3 \mathrm{~m} / \mathrm{s}\right)$ one finds that the damage radius is equal to $0.56 \mathrm{~m}$ and the corresponding $R_{d} / r_{h}$ ratio is:

$$
\frac{R_{d}}{r_{h}}=23.3
$$

This is a maximum value since the site calibration factor is unknown and hence could not be introduced.

\subsubsection{The Sher Quasi-Static Approach}

The Sher Quasi-Static Approach is, in general, not easily applied since it requires knowing the adiabatic expansion constant which applies for the reduced pressure applied to the borehole wall. Here, the two limiting conditions will be used. Case 1 assumes that $\gamma=3$, and Case 2 assumes that $\gamma=1.27$.

Introducing the wall pressure $\left(P_{e}\right.$ wall $\left.=598 \mathrm{MPa}\right)$ one finds that:

Case 1: Maximum

$$
\frac{R_{d}}{r_{h}}=18
$$

the expected damage radius is:

$$
R_{d}=18(0.024)=0.43 m
$$

Case 2: Minimum

$$
\frac{R_{d}}{r_{h}}=14
$$

the expected damage radius is:

$$
R_{d}=14(0.024)=0.34 m
$$

\subsection{Summary of the perimeter hole results}

As might be expected, the different approaches yield somewhat different estimates of the damage radius. They are summarised in Table 3. 
Table 3 Summary of the perimeter hole results

\begin{tabular}{lll}
\hline Approach & $\boldsymbol{R}_{d} / \boldsymbol{r}_{\boldsymbol{h}}$ & $\boldsymbol{R}_{\boldsymbol{d}}(\boldsymbol{m})$ \\
\hline Modified Ash Pressure-based & 17 & 0.4 \\
Modified Ash Energy-based & 17 & 0.4 \\
Holmberg Explosive Factor & 17 & 0.4 \\
Neiman Hydrodynamic & $23(\max )$ & $0.6(\max )$ \\
Sher Quasi-Static & $14-18$ & $0.3-0.4$ \\
\hline
\end{tabular}

These results can be re-grouped depending upon whether they are explosive energy or explosive pressure based. This has been done in Table 4 .

Table 4 Perimeter hole results organised by energy and pressure techniques

\begin{tabular}{lll}
\hline Energy-based Approach & $\boldsymbol{R}_{\boldsymbol{d}} / \boldsymbol{r}_{\boldsymbol{h}}$ & $\boldsymbol{R}_{\boldsymbol{d}}(\boldsymbol{m})$ \\
\hline Modified Ash Energy-based & 17 & 0.4 \\
Holmberg Explosive Factor & 17 & 0.4 \\
Neiman Hydrodynamic & $23(\mathrm{max})$ & $0.6(\mathrm{max})$ \\
\hline Pressure-based Approach & $\boldsymbol{R}_{\boldsymbol{d}} / \boldsymbol{r}_{\boldsymbol{h}}$ & $\boldsymbol{R}_{\boldsymbol{d}}(\boldsymbol{m})$ \\
\hline Modified Ash Pressure-based & 17 & 0.4 \\
Sher Quasi-Static & $14-18$ & $0.3-0.4$ \\
\hline
\end{tabular}

In Figure 34, circles of radius $R_{d}=0.4 \mathrm{~m}$ have been drawn around each of the reliever holes.

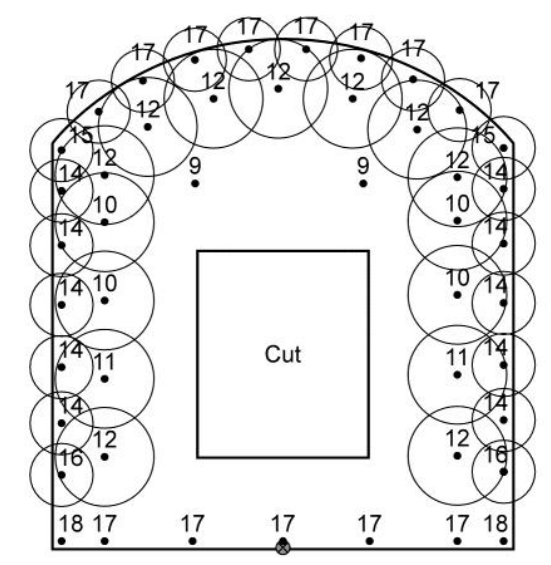

Figure 34 Addition of the damage radius circles around the perimeter holes

As can be seen, the circles extend $0.4 \mathrm{~m}$ outside of the perimeter and there is considerable overlap. This suggests that the perimeter hole design might be re-visited.

\subsection{Summary}

The five different approaches to estimating the damage radii around the fully-coupled easer holes and the de-coupled perimeter holes have been applied to the provided design. Although the results from the five design approaches differed somewhat, in general, there was good agreement. The results of the analysis would suggest that some relatively small modifications might be tried. The number and locations of the easer holes are generally correct. Figure 35 shows a slightly modified design from that currently being used. 


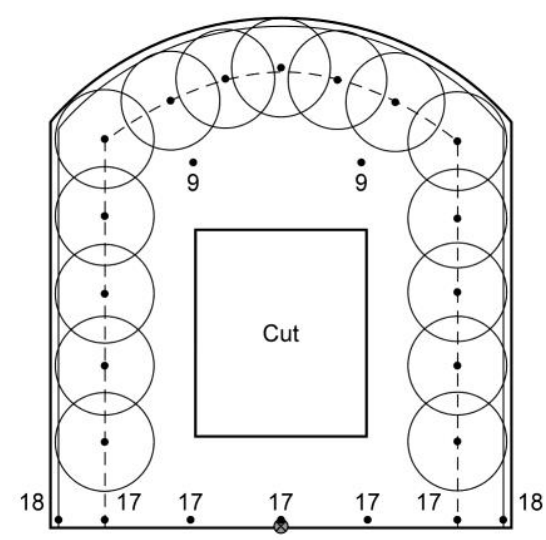

Figure 35 The modified easer hole design

The NIOSH design approach recommends that the perimeter holes be positioned to remove the rock cusps remaining between the easer holes. Figure 36 shows the new locations of the perimeter holes based on applying this principle.

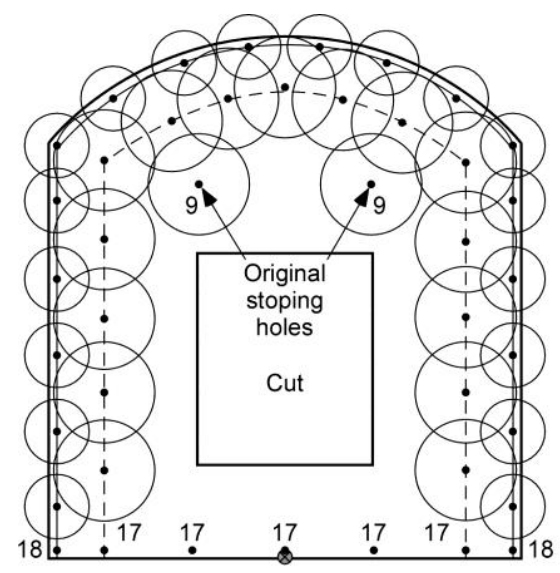

Figure 36 The modified easer hole design with the perimeter holes added

As can be seen, it is a just-touching rather than overlap design. The number of holes has been reduced from 22 to 18 while maintaining adequate coverage. Here, the holes have been placed to remove the remaining cusps and to smooth the excavation. On this figure the current positions of the stoping holes are shown. To achieve better energy coverage, it is suggested that two more stoping holes be added and the final pattern would appear as in Figure 37. 


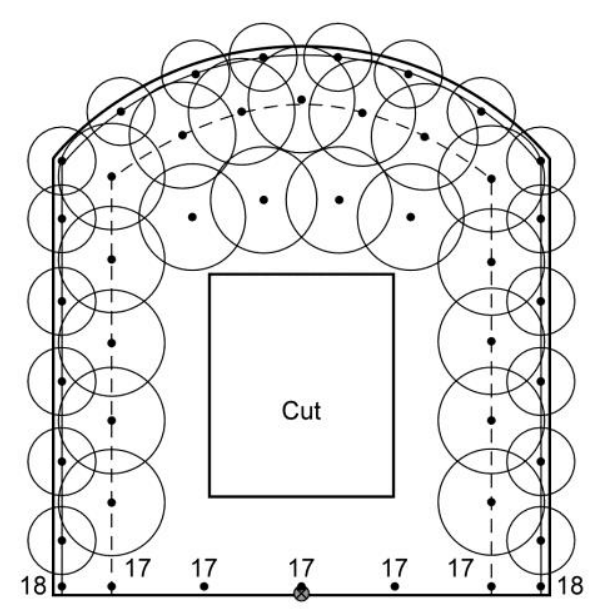

\section{Figure 37 Final suggested design with the addition of two stoping holes above the cut}

In summary, application of the NIOSH design approach to the given design revealed very similar results to what has been found to be successful by the mine. Some slight adjustments might be tried to achieve even better energy coverage. Because the damage circles associated with the perimeter holes extend out beyond the desired profile, some overbreak might be expected.

\section{The practical way forward}

Work still needs to be done concerning the development of a best practical blast damage radius predictor but the results obtained using the five different techniques presented in this paper are encouraging. It is hoped that mining operations will start to employ the suggested approach and provide feedback concerning their experience. In this way, a catalogue of experience can be compiled and the results generalised. For some readers, you might start now by simply sketching one of your blast patterns and superimposing damage radius circles. As a first approximation, employ the Modified Ash Pressure-based Approach since it is the easiest. For those of you without a blast design in your heads, presented in Figure 38 is a design for a $4.5 \times 4.0 \mathrm{~m}$ drift provided by Holmberg (1982) using the burden-spacing equations developed by Langefors and Kihlström (1963). As can be seen, it has perimeter control for the roof but not the walls.

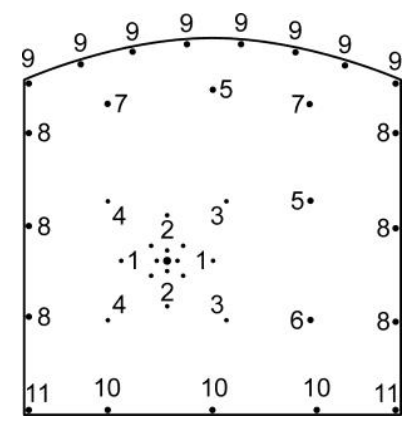

Figure 38 A design provided by Holmberg (1982)

In Figure 39, damage radius circles have been superimposed on several of the holes. The gaps in the coverage are clearly seen suggesting improvement opportunities. 


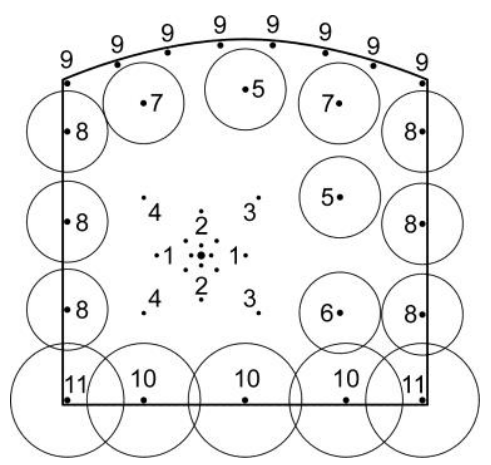

Figure 39 Superposition of influence circles on the Holmberg (1982) design

\section{Conclusions}

Effective drifting practices are a very important part of modern caving systems. Today, available drilling and blasting technology has developed to the point that there is no reason why the rock mass cannot be 'cut as with a knife', if so desired. One of the missing items in the overall process is a simple, but technically sound, method for assigning the damage radius produced by a particular explosive-hole-rock combination. It is hoped that the industry will find some of the ideas and approaches described in this paper to be of benefit in that regard. Through the application of careful perimeter blasting practices, the damage to the remaining rock will be minimal, the shape of the opening will be similar to the as-designed, and the succeeding operations such as scaling and rock reinforcement will be easier and more effective. This translates into improved safety and better economy, both of which are essential to modern mining.

\section{Acknowledgements}

The work presented in this paper has been performed as part of the project, Improved Mine Safety Through Optimised Rock Extraction. The overall project goal is to develop/improve cautious blasting techniques and to encourage their use in underground metal/non-metal mines. By minimising the extent of loose and/or damaged rock surrounding the blasted opening, mine worker exposure to ground fall hazards will be significantly reduced. It is a substantial effort with a number of project members. The author would like to specifically acknowledge the technical contributions made by Steve Iverson, Jeff Johnson and Doug Tesarik. Kenneth Strunk is warmly thanked for making the drawings. Christine Ribble was instrumental in putting the manuscript in final form. The work could not be done without the continuing support of NIOSH management. Appreciation is expressed to the Newcrest Mining Company and the El Teniente Division of Codelco for permission to include some of the figures. In the end, the responsibility for the paper and its contents falls on the author. Every effort has been made to prevent errors from entering but they might have. For that, I am sorry. Your constructive criticism, suggestions for improvement, and documentation concerning the successes/failures you have experienced in applying the approach will be greatly appreciated.

\section{References}

Ash, R.L. (1963) The Mechanics of Rock Breakage, Pit and Quarry, Part I, pp. 98-112 (Aug), Part II, pp. 118-123 (Sept), Part III, pp. 126-131 (Oct), Part IV, pp. 109-118 (Nov).

Collins, J.H. (1875) Principles of Metal Mining, William Collins Sons, London, 149 p.

Holmberg, R. and Persson, P.A. (1979) Design of Tunnel Perimeter Blasthole Patters to Prevent Rock Damage, In Proceedings Tunnelling, M.J. Jones (ed), Institution of Mining and Metallurgy, London.

Holmberg, R. (1982) Charge Calculations for Tunnelling, Underground Mining Methods Handbook, W. Hustrulid (ed), AIME, New York, pp. 1580-1589.

Hustrulid, W. (1999) Blasting Principles for Open Pit Mining, Volumes 1 and 2, Balkema, Rotterdam.

Hustrulid, W. and Lu, W. (2002) Some General Design Concepts Regarding the Control of Blast-Induced Damage during Rock Slope Excavation, In Proceedings Frogblast 7, Rock Fragmentation by Blasting, Wang and Xuguang (eds), Metallurgical Industry Press, Beijing, pp. 595-604.

Hustrulid, W. and Johnson, J. (2008) A Gas Pressure-based Drift Round Blast Design Methodology, In Proceedings the 5th International Conference and Exhibition on Mass Mining, MassMin 2008, H. Schunnesson and E. Nordlund (eds), 9-11 June 2008, Luleå, Sweden, Luleå University of Technology Press, Luleå, pp. 657-669. 
Langefors, U. and Kihlström, B. (1963) The Modern Technique of Rock Blasting, John Wiley, New York, 405 p.

Neiman, I.B. (1979) Determination of the Zone of Crushing of Rock in Place by Blasting, Soviet Mining Science, Vol. 15(5), pp. 480-499.

Neiman, I.B. (1984a) Mathematical Model of the Explosive Action of a Fracturing Charge in a Ledge Rock Mass, Soviet Mining Science, Vol. 19(6), pp. 494-499.

Neiman, I.B. (1984b) Correction of the Hole Charge Parameters in Rock Bench Breaking, Soviet Mining Science, Vol. 20(5), pp. 385-388.

Neiman, I.B. (1986a) Modelling the Explosion of a System of Borehole Charges in a Scarp, Soviet Mining Science, Vol. 22(2), pp. 108-113.

Neiman, I.B. (1986b) Volume Models of the Action of Cylindrical-Charge Explosion in Rock, Soviet Mining Science, Vol. 22(6), pp. 455-463.

Olsson, M. and Bergqvist, J. (1993) Crack Growth in Rock During Cautious Blasting, SveBefo Rapport 3 (in Swedish), Swedish Rock Engineering Research, Stockholm.

Persson, P.A., Holmberg, R. and Lee, J. (1994) Rock Blasting and Explosives Engineering, CRC Press, Boca Raton, $540 \mathrm{p}$.

Sher, E.N. and Aleksandrova, N.I. (2007) Effect of Borehole Charge Structure on the Parameters of a Failure Zone in Rocks Under Blasting, Journal of Mining Science, Vol. 43, No. 4, pp. 409-417.

Sher, E.N. and Aleksandrova, N.I. (1997) Dynamics of Development of Crushing Zone in Elasto plastic Medium in Camouflet Explosion of String Charge, Journal of Mining Science, Vol. 33, No. 6, pp. 529-535.

Sher, E.N. (1997) Taking into Account the Dynamics in Description of Fracture of Brittle Media by an Explosion of a Cord Charge, Journal of Applied Mechanics and Technical Physics, Vol. 38, No. 3, pp. 484-492.

Tesarik, D.R. and Hustrulid, W. (2009) A Hydrodynamics-based Approach for Predicting the Blast Damage Zone in Drifting as Demonstrated Using Concrete Block Data, Blasting and Fragmentation, Vol. 3, No. 2, August, pp. 141-166. 


\section{Appendix 1 Co-volume approach for making de-coupled charge calculations}

The explosive wall pressure is given by:

$$
P_{e}=\frac{1}{8} \rho_{e}(V O D)^{2}
$$

where:

$P_{e} \quad=\quad$ pressure in MPa.

$\rho_{e} \quad=\quad$ explosive density $\left(\mathrm{kg} / \mathrm{m}^{3}\right)$.

$V O D=$ detonation velocity $(\mathrm{km} / \mathrm{s})$.

For fully-coupled charges, the wall pressure is the same as the explosion pressure:

$$
P_{\text {ewall }}=\frac{1}{8} \rho_{e}(V O D)^{2}
$$

for de-coupled charges, the co-volume approach must be applied. The basic equation is:

$$
P_{\text {ewall }}=P_{e}\left(\frac{v_{e}-\alpha_{e}}{v_{h}-\alpha_{h}}\right)=P_{e} \frac{V_{e}}{V_{h}}
$$

where:

$$
\begin{gathered}
V_{e}=v_{e}-\alpha_{e} \\
V_{h}=v_{h}-\alpha_{h} \\
v_{e}=\frac{1}{\rho_{e}} \\
\alpha_{e}=1.1 e^{-0.473 / v_{e}} \\
v_{h}=\frac{1}{\rho_{e}}\left(\frac{A_{h}}{A_{e}}\right) \\
\alpha_{h}=1.1 e^{-0.473 / v_{h}}
\end{gathered}
$$

Equation (A3) is used to calculate the average wall pressure for different de-coupled charge arrangements. Figures A1 and A2 are plots of borehole wall pressure as a function of area coupling for detonating cord.

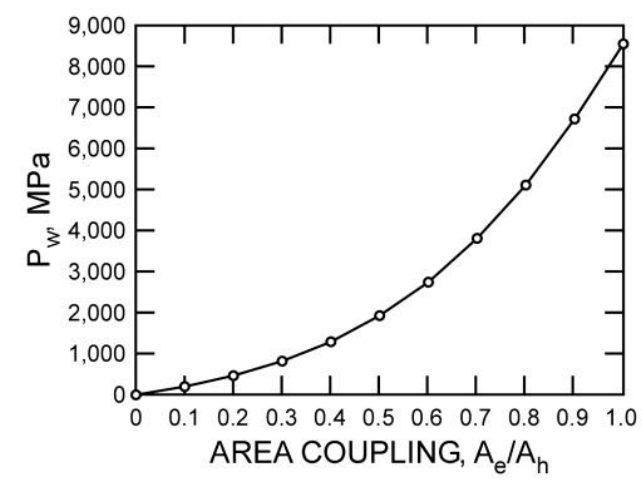

Figure A1 Borehole wall pressure as a function of area coupling for PETN over the full-coupling range 


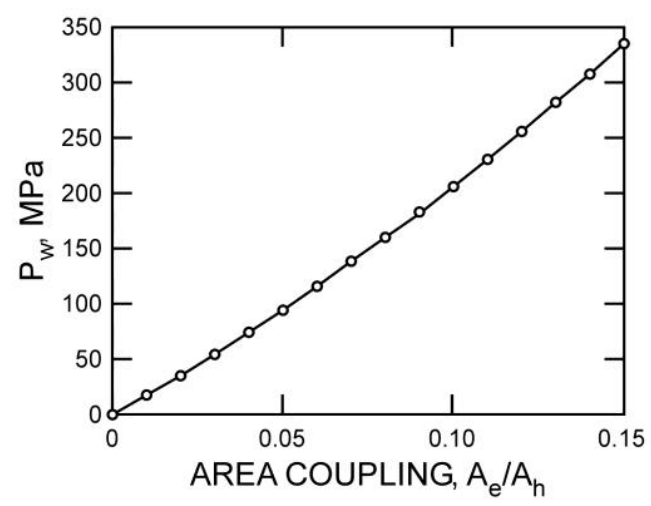

Figure A2 Borehole wall pressure as a function of area coupling for PETN over the practical coupling range

The following values have been used in their construction:

$\rho_{e}(P E T N)=1.4 \mathrm{~g} / \mathrm{cm}^{3}$.

$V O D=7,000 \mathrm{~m} / \mathrm{s}$.

$P_{e} \quad=\quad 8,575 \mathrm{MPa}$.

When the de-coupled charges are in tubes that extend the length of the hole, Equation (A8) can be written as:

$$
v_{h}=\frac{1}{\rho_{e}}\left(\frac{d_{h}}{d_{e}}\right)^{2}
$$

Figure A3 is a plot of borehole wall pressure as a function of the diameter coupling for ANFO.

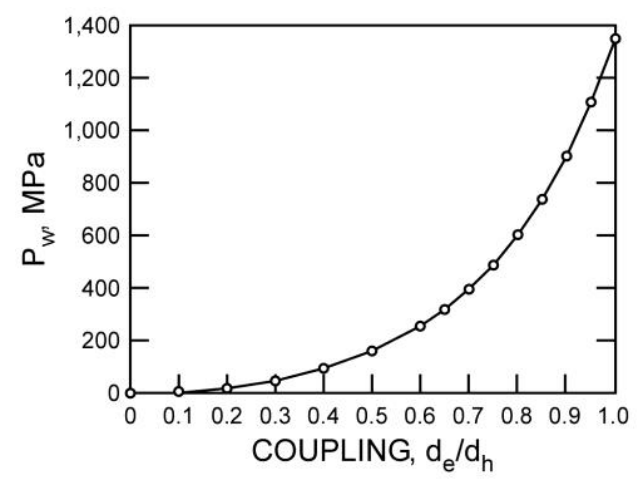

Figure A3 Borehole wall pressure as a function of diameter coupling for ANFO over the full-coupling range

The following values were used in its construction:

$\rho_{e}(A N F O)=0.85 \mathrm{~g} / \mathrm{cm}^{3}$.

$V O D=3,500 \mathrm{~m} / \mathrm{s}$.

$P_{e} \quad=\quad 1,300 \mathrm{MPa}$.

In some cases, air-decking involving ANFO is used in the perimeter holes. It is then convenient to plot the wall pressure versus coupling curves using the charged length $\left(L_{e}\right)$ to hole length $\left(L_{h}\right)$ ratio. This has been done for ANFO in Figure A4. 


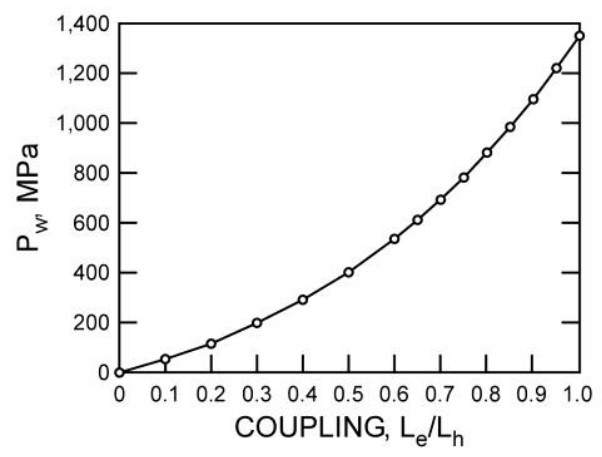

Figure A4 Average borehole wall pressure as a function of length coupling for ANFO. This is appropriate for air-decking applications in particular 
